\title{
1 Ultimate bond strength assessment of uncorroded and corroded reinforced 2 recycled aggregate concretes
}

\author{
3 Ignasi Fernandez ${ }^{1}$, Miren Etxeberria*¹, Antonio R. Marí ${ }^{1}$ \\ $4{ }^{1}$ Department of Construction Engineering, Polytechnic University of Catalonia, Jordi Girona, 1-3, \\ 5 Barcelona 08034, Spain. \\ 6 *corresponding author. Telephone: +34 934011788, email: miren.etxeberria@upc.edu \\ 7 Keywords: \\ 8 steel reinforced concrete; modelling studies; rust
}

9 Abstract:

10 This experimental study assesses the bond performance of recycled aggregate concretes (RAC) with

11 embedded uncorroded and corroded steel bars. The RAC were produced using $20 \%$, 50\% and 100\%

12 of coarse recycled aggregates obtained from the crushing of waste $40 \mathrm{MPa}$ compressive

13 strength concrete. Three degrees of corrosion were reached on the steel bars. The uncorroded RAC

14 specimens presented a comparable bond strength to that of conventional concrete (CC). Low 15 corroded RAC specimens presented better bond performance and later superficial cracking when 16 compared to those of CC. At a higher corrosion degree, all concretes presented a similar bond 17 capacity. The ultimate bond strength estimation models used for CC were adequate for its 18 prediction on RAC. 


\section{1. Introduction}

22 Corrosion of the steel bars is one of today's most frequent and significant type of damage,

23 in existing reinforced concrete structures. Therefore, the study of the structural effects of

24 bars corrosion is crucial in determining the structural performance and residual strength of

25 impaired structures. One of the most severe reinforcement corrosion effects is the change in

26 bond properties between steel and concrete. Moreover, volumetric expansion of corrosion

27 products causes serious problems by inducing splitting stresses along corroded

28 reinforcement, with possible resulting damage to the surrounding material. Generally, the

29 splitting stresses are not tolerated by concrete, resulting in cracking and eventually spalling

30 of the cover. As the reinforcement becomes more exposed, the corrosion rate may increase

31 and facilitate the deterioration process.

32 Steel reinforcement unconfinement due to cover cracking or spalling of concrete cover, as

33 well as rust between both materials, quickly decreases the bond strength, thus changing the

34 structural behaviour and inducing anchorage failures. Many researchers have extensively

35 studied the effect of the corrosion process on bond deterioration extensively. Several

36 studies have dealt with the investigation of the parameters that may influence the bond and

37 anchorage capacity of corroded structures [1-5]. Models studying the interaction between

38 both materials, and numerous experimental studies identifying and studying this

39 phenomenon can be found in the literature on the subject [6-9]. Even though, the literature

40 on works covering bond behaviour on recycled aggregates is very sparse [10-17].

41 The increasing amount of construction wastes coming from old and deteriorated structures

42 at the end of their service life has a relevant environmental impact on the construction

43 sector as the results of the economic benefits of using the wastes produced in the form of 
44 recycled concrete aggregates (RCA) in the concrete employed in reinforced concrete 45 production. Wastes from older structures yield fragments in which the aggregate is 46 contaminated with various different substances such as gypsum, asphalt, etc. A proper

47 treatment of the recycled aggregate, as well as an accurate production process, results in 48 recycled aggregate concrete (RAC) being a very suitable option to reduce the overall cost in 49 the construction sector [18]. Over the past 50 years, the use of RCA has been profoundly 50 studied for concrete production [18-27] and the resulting studies maintain that the primary 51 weakness of RCA is its high porosity, which could directly influence a decrease in the 52 compressive strength and durability of concretes produced with those aggregates.

53 Recent studies have tried to determine the bond between both the RAC and the steel with 54 respect to that of conventional concrete (CC) and steel [13]. These studies manifest that a 55 reduction of bond strength could be associated with the amount of recycled aggregate used 56 in the mixture. Several authors $[13,15,16]$ reported reductions of $6-8 \%$ up to $30 \%$ of bond 57 capacity, nevertheless other researchers’ work [10] noted differences of approximately 1\% 58 of the bond strength of recycled aggregate concrete with respect to that of CC concrete. 59 Although the reduction in bond strength is strongly related to the concrete's compressive 60 strength, it is also dependent on other parameters such as steel bar rib geometry and the 61 position and orientation of the bars during casting. The amount of concrete cover also has 62 an important influence on this phenomenon [10,28-33].

63 In this experimental study of the bond strength and bond behaviour between recycled 64 aggregate concrete and reinforcement steel, either corroded or uncorroded, using the direct 65 pull-out tests was presented. Two experimental phases were conducted, one with 66 uncorroded and another with corroded steel bars embedded in RAC and CC concrete cube 
67 specimens. For that purpose, four different concrete mixtures were cast in each phase by 68 replacing $0 \%$ (using $100 \%$ of natural aggregates, CC concrete), 20\% (RAC-20), 50\%

69 (RAC-50) and 100\% (RAC-100) of natural coarse aggregates for coarse recycled concrete 70 aggregates. The obtained results for RAC concretes were compared with the results 71 obtained from the CC concrete, before finally being compared to other models encountered

72 in the literature referring to the bond strength capacity of reinforced conventional and 73 recycled concrete.

\section{2. Materials}

\section{$75 \quad 2.1$ Materials}

76 Type I Portland cement, CEM I 42.5R, was used in concrete mixtures with rapid hardening

77 and 42.5 MPa characteristic strength cement. The chemical properties of cement are given 78 in Table 1.

79 Table 1. Chemical composition of cement

\begin{tabular}{cccccccccc}
\hline Composition & $\mathrm{SiO}_{2}$ & $\mathrm{Fe}_{2} \mathrm{O}_{3}$ & $\mathrm{Al}_{2} \mathrm{O}_{3}$ & $\mathrm{CaO}$ & $\mathrm{MgO}$ & $\mathrm{K}_{2} \mathrm{O}$ & $\mathrm{Na}_{2} \mathrm{O}$ & $\mathrm{SO}_{3}$ & LOI \\
\hline$\%$ & 19.16 & 3.56 & 5.04 & 62.9 & 1.66 & 0.75 & 0.15 & 3.54 & 3.25 \\
\hline
\end{tabular}

80

81 Natural limestone, fine (FA, 0/4 mm) and coarse aggregates (two fractions; CA1 of 4/12

$82 \mathrm{~mm}$ and CA2 fraction of 12/20 mm) were used for concrete production. Physical properties, 83 density and absorption, and the grading distributions are described in Table 2 and Fig. 1, 84 respectively. The properties of the fine and coarse aggregates were determined according to 85 EN specifications. All fractions of natural aggregates satisfy the requirements specified by 86 the Spanish Standard of Structural Concrete [34]. 
87 RCA aggregates were obtained by crushing rejected $40 \mathrm{MPa}$ compressive strength concrete

88 produced by a precast concrete company. The properties of RCA of density, absorption and

89 grading size are shown in Table 2 and Fig. 1, respectively. It was found that the density of

90 RCA was found to be lower than that of the natural aggregates and the absorption capacity

91 was higher. The porosity of RCA determined by mercury Intrusion porosimetry (MIP) was

$928.63 \%$ and its average pore diameter was $0.048 \mu \mathrm{m}$. The grading was defined by $4 / 20 \mathrm{~mm}$,

93 which complied with the Spanish Standard of Structural concrete regulations [34] in its

94 employment for recycled concrete production and it was used in substitution of CA1 and

95 CA2 natural coarse aggregates.

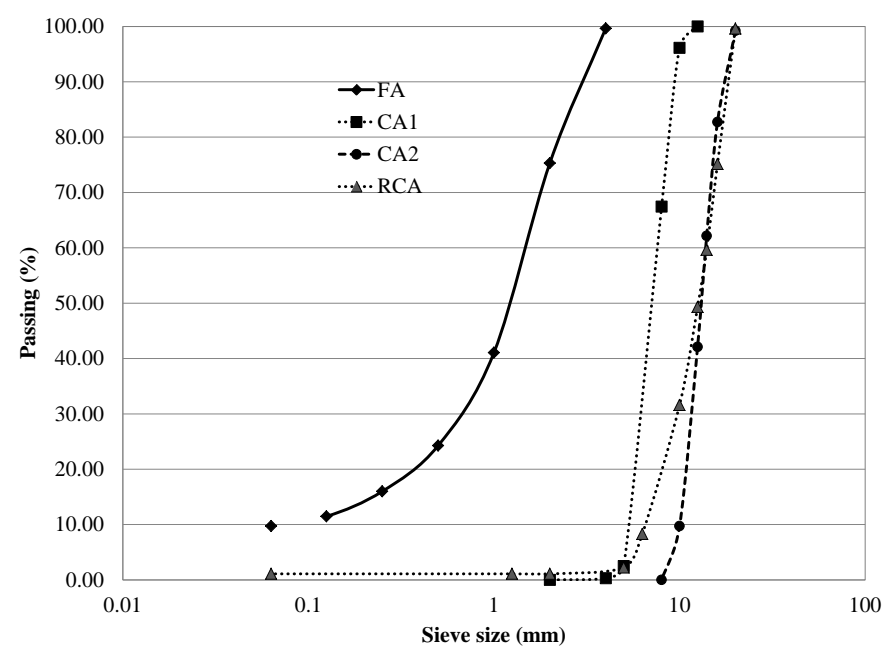

Fig. 1. Grading distribution of fine natural aggregates (FA) and coarse natural (CA1 and

98 CA2) and recycled aggregates (RCA)

99 Table 2. Dry density and water absorption capacity of aggregates

\begin{tabular}{lcccc}
\hline Properties & CA2 12/20mm & CA1 4/12mm & FA 0/4mm & RCA \\
\hline Dry density $\left(\mathrm{kg} / \mathrm{dm}^{3}\right)$ & 2.65 & 2.64 & 2.58 & 2.30 \\
Water absorption (\%) & 0.67 & 0.87 & 1.68 & 5.91 \\
\hline
\end{tabular}


101 At concrete production $4 \% \mathrm{NaCl}$ in weight of cement was added to the mixture; the aim of 102 which was the depassivation of the steel inside the concrete and the causing of a conductive 103 medium to facilitate the corrosion procedure. Superplasticizer was also used to provide the 104 desired workability of the mixture.

1052.2 Concrete mix proportions

106 The four mixtures (Conventional concrete, CC; concrete produced with 20\% of RCA, 107 RAC-20; concrete produced with 50\% of RCA, RAC-50; concrete produced with $100 \%$ of 108 RCA, RAC-100) were prepared and cast. The replacement of raw, coarse aggregates for 109 recycled coarse aggregates was carried out according to the volume.

110 The mix proportion of CC concrete was defined with $300 \mathrm{~kg}$ of cement and a total water111 cement ratio of 0.5 for concretes exposed to a marine and chloride environment as 112 described by the Spanish Structural Concrete code [34]. The effective water-cement ratio of 113 CC concrete was determined and maintained constant in all RAC concretes. The total w/c 114 ratio of RAC was higher than for CC, due to higher absorption capacity of RCA[24].

115 It is taken as understood that the effective water / cement ratio of the concretes is the ratio 116 between the effective water (free water which reacts with cement) and total cement weight.

117 The effective water was determined by first calculating the total water used for concrete 118 production and then subtracting both the water absorbed by the aggregates and the moisture 119 present in RCA during concrete production. The previously mentioned water amount 120 absorbed by aggregates at concrete production is termed as the effective water absorption 121 capacity of aggregates and it was determined experimentally. The experiment consisted of 122 submerging the aggregates in water for 20 minutes [24]. The effective water absorption 
123 capacity of natural coarse and fine aggregates was $20 \%$ and $80 \%$ of their total water 124 absorption capacity, respectively. The recycled aggregates had an effective water 125 absorption capacity of 70\% of their total capacity. (The total water absorption capacity of 126 the aggregates is described in Table 2). The effective w/c ratio on CC concrete was 127 approximately 0.45 and it mantained constant in all RAC concretes.

128 The control of the effective water/cement ratio in the production process of recycled 129 aggregate concrete can only be obtained by using recycled aggregates with aproximately a 130 moisture level of between $80 \%-90 \%$ of their total absorption capacity [24] (in order to 131 reduce their total absorption capacity [26]). The coarse recycled concrete aggregates were 132 wetted the day before use via a sprinkler system and then covered with a plastic sheet so as 133 to maintain their humidity (aprox. at $80 \%$ of their absorption capacity) until used in 134 concrete production. During concrete production, recycled aggregates absorbed a certain 135 amount of free water due to their initial moderate moisture content. This effectively lowers 136 their w/c ratio in the interfacial transition zone (ITZ), consequently improving the 137 interfacial bond between the aggregates and cement [27]. It is well known that the 138 compressive strength of concrete made with saturated aggregate is lower than concrete 139 made with air dried aggregates due to the adverse effect of the bleeding of the saturated 140 aggregates [23].

141 Concrete mix proportions were defined according to their maximum volumetric 142 compaction. This mix proportion for conventional concrete (CC) was defined as 50\% of 143 fine aggregates and $50 \%$ of coarse aggregate. The distribution of coarse aggregate was $30 \%$ 144 CA1 4/12mm and $70 \%$ of CA2 $12 / 20 \mathrm{~mm}$. The same volume of CA1 and CA2 was 145 replaced by RCA for each recycled aggregate concrete production. 
146 Table 3 shows the mix proportions used. The weight of aggregates is given as their dry

147 weight. The total amount of water was considered, including the effective absorbed water

148 by aggregates as well as the $80-90 \%$ of humidity of recycled aggregates at concrete

149 production. $4 \%$ of $\mathrm{NaCl}$ and $1 \%$ of superplasticizer were used in all concretes with respect

150 to cement weight.

151 Table 3. Mix proportions of the concretes mixtures

\begin{tabular}{lcccc}
\hline Material (1000 litres) & CC & RCA-20 & RCA-50 & RCA-100 \\
\hline Cement (kg) & 300 & 300 & 300 & 300 \\
Total Water (kg) & 150 & 159 & 172 & 194 \\
Effective w/c & 0.45 & 0.45 & 0.45 & 0.45 \\
FA 0/4mm & 976 & 976 & 976 & 976 \\
CA1 4/12mm & 210 & 168 & 105 & - \\
CA2 12/20mm & 765 & 612 & 383 & - \\
RCA & - & 171 & 428 & 855 \\
NaCl (weight of & $4 \%$ & $4 \%$ & $4 \%$ & $4 \%$ \\
cement) & & & & \\
Superplasticizer & $1 \%$ & $1 \%$ & $1 \%$ & \\
(weight of cement) & & & & \\
\end{tabular}

\section{Experimental campaign and test procedure}

153 The concrete compressive strength was determined for all concrete types. Bond strength

154 between concrete and steel bars both corroded and uncorroded were analysed by means of 155 two experimental phases.

\subsection{Compression test}

157 The compressive strength of concrete was determined using a compression machine with a 158 loading capacity of $3000 \mathrm{kN}$. The compressive strength was measured at the age of 28 days 159 following UNE-EN 12390-3 specifications. Three cylindrical specimens (100mm of 160 diameter and $200 \mathrm{~mm}$ of length) were used for each type of concrete produced. 
162 The experimental work presented here focuses on the direct pull-out test of both the natural

163 aggregate concrete, and the recycled aggregate concretes, reinforced with steel bars. The

164 underlying purpose of the work focusing on the characterization of the corresponding bond

165 behaviour. Pull-out test is a widely used test employed to obtain the local bond behaviour

166 for short embedded length steel specimens. The typical assumption for short pull-out tests

167 with ribbed steel reinforcement bars, defined by embedment length of less than five times

168 the bar diameter, is that the distribution of bond stresses is uniform along the bonded

169 section $[35,36]$. Accordingly, the hypothesis of the uniform bond stresses was assumed and

170 the local bond stress could be estimated as:

$171 \quad$ (1) $\tau=P / \pi \Phi L$

172 where, $\mathrm{P}$ is the applied load, $\Phi$ is the nominal diameter of the steel bar, and $\mathrm{L}$ is the 173 embedded length.

174 The experimental study was divided into two phases. In experimental Phase 1 the test was 175 performed according to the code recommendations [37]. In experimental Phase 2, some 176 concrete specimens were summited to accelerated corrosion and consequently the 177 embedded bar design was modified with respect to the criteria defined by the code. The 178 pull-out test were carried out through the use of 100x100 mm cubic specimens which had 179 embedded steel in the upper face. For the purpose of this study the top, bottom and sides of 180 the concrete cube shall be known as upper face, bottom face and lateral faces. 
183 The experimental setup was conducted following the code recommendations [37] and using 184 a specific fatigue machine INSTRON 8800.

185 Steel bars of $\phi 12 \mathrm{~mm}$ were embedded in the centre of the $100 \times 100 \mathrm{~mm}$ cubic concrete 186 specimens. The steel bars completely crossed the cube section of $100 \mathrm{~mm}$. A piece of 187 plastic tube was used to debond $50 \mathrm{~mm}$ of the steel bar from the concrete, leaving the other $18850 \mathrm{~mm}$ to bond with the concrete (see Fig. 2a). In total 16 cubic specimens were cast, four 189 for each concrete type.

190 (a)

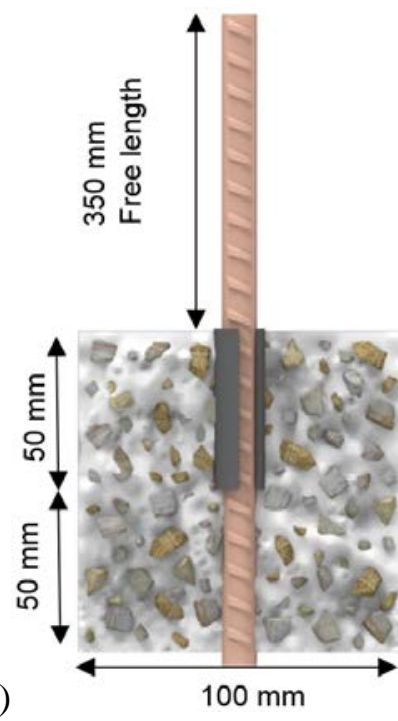

(b)

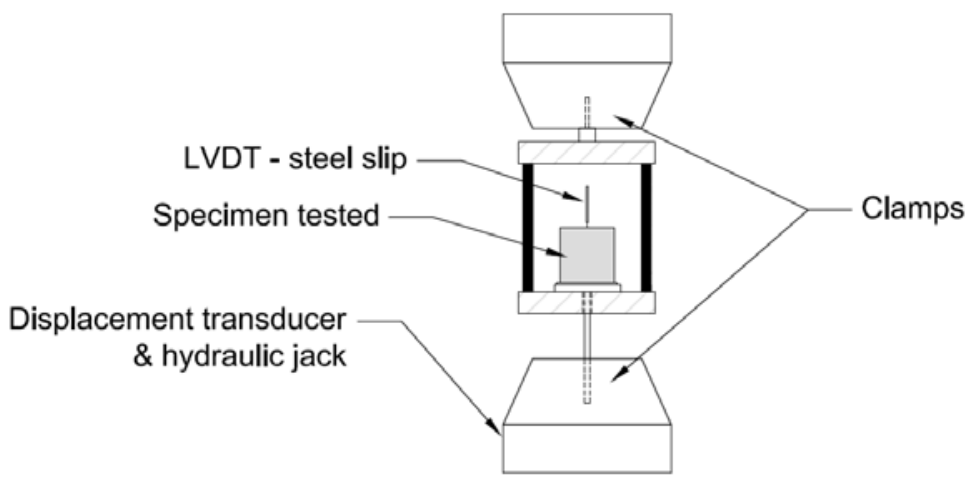

191 Fig. 2. (a) Concrete specimen description (phase 1) (b) Test setup, direct pull-out test

192 The total slip between both the concrete and the steel was measured during the test. An 193 LVDT was affixed to the concrete cube at the specimen's bottom in order to register the 194 total rebar slip.

195 The hydraulic jack clamps were attached to the steel bar-end. The load was applied directly 196 to the bar by means of control displacement, in order to achieve results on both the pre and 197 post peak behaviour up to failure, as well as the residual bond capacity. The applied load 
198 and the LVDT readings were recorded every half a second by means of a DAQ. The test 199 was conducted using a constant velocity of $0.2 \mathrm{~mm} / \mathrm{min}$. Fig. $2 \mathrm{~b}$ shows the experimental 200 setup.

201 3.2.2 Pull-out test: Phase 2

202 The Phase 2 test specimen design was modified with respect to that defined by the code 203 [37]. The reason for this modification was to facilitate a simpler and more reliable method 204 of the steel corrosion procedure. 16 cubic specimens of $100 \mathrm{~mm}$ were cast for each 205 designed concretes. $\phi 10 \mathrm{~mm}$ steel bar diameter were used in the experimental Phase 2 and 206 the bars, as Fig. 3 shows, did not fully cross the whole concrete section of $100 \mathrm{~mm}$. The 207 free steel length for all the specimens, was $350 \mathrm{~mm}$ and the bonded section was $50 \mathrm{~mm}$.

208 The bars were embedded from the centre of the upper surface of the cubic specimens to a 209 length which was equivalent to five times that of the steel bar diameter. The moulds used 210 were specially designed in order to ensure that the bars were fixed at the same position in 211 all the specimens. Fig. 3 describes the test specimens and the established setup. $45 \mathrm{~mm}$ of 212 concrete covered the embedded bar in all directions. This configuration ensured the same 213 corrosion degree guaranteed in all the embedded section of the steel bar. 

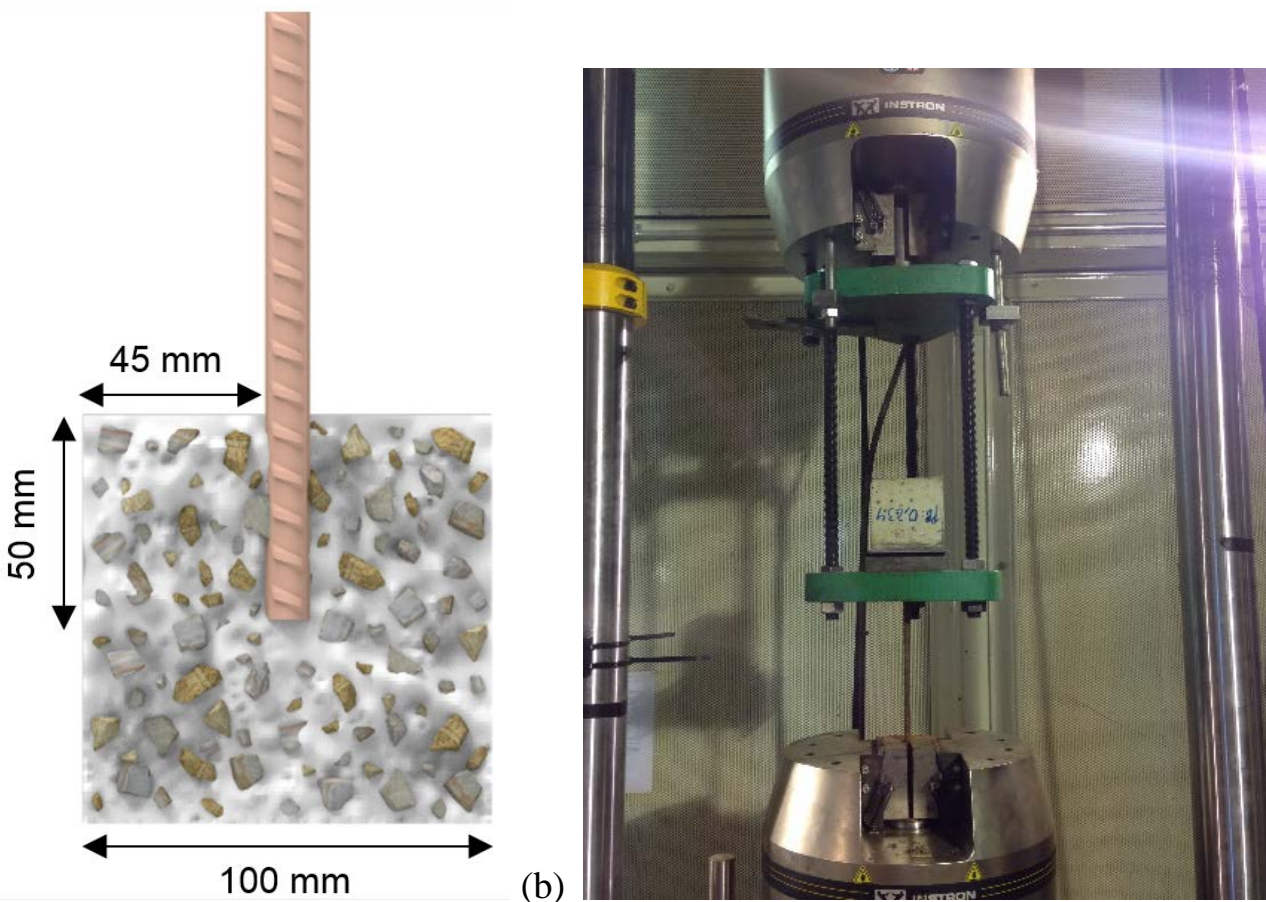

215 Fig. 3. (a) Concrete specimen description (Phase 2) (b) Pull-out test setup

216 In this study case hydraulic jack clamps also were attached to the steel bar-end in order to

217 pull the bar out of the concrete. The tests were conducted by means of displacement 218 control, of $0.2 \mathrm{~mm} / \mathrm{min}$, until failure or until the residual bond load was reached.

219 The load was applied directly to the bar via a hydraulic jack controlled by a load cell. The 220 total displacement, as well as the applied load, were registered. Each measurement was 221 recorded and stored every half a second by means of a DAQ. The registering of the real slip 222 between both materials was impossible to carry out as the bar did not completely cross the 223 specimens. Thus, the displacement values expressed included all the other external 224 deformations such as slip in the clamps, neoprene compression, concrete deformation, free 225 length steel bar deformation, etc. Consequently, the slip values obtained in Phase 1 and 226 Phase 2 were not directly comparable. The $\tau_{\max }$ being the only comparable data. 


\subsubsection{Corrosion method}

229 Corrosion of steel reinforcement was induced by means of the passing of an electrical 230 current. Following Faraday’s law, Eq. 2, it is possible to determine the weight loss of steel 231 at any given time through corrosion, due to the applied intensity of the electrical current $232 \mathrm{I}(\mathrm{t})$, together with the diameter and exposed length of bar.

$$
E=\frac{m_{F e} \cdot \int I \cdot d t}{V \cdot F}
$$

234 Where, $m_{F e}$ is the atomic mass, $\mathrm{V}$ is the steel Valencia that is equal to two and $\mathrm{F}$ is the 235 Faraday's constant. As the applied intensity was a constant input during the whole duration 236 of the test, it is possible to rewrite Faraday’s law as Equation3, in order to determine the 237 weight loss of steel.

$$
\Delta m=\frac{m_{F e} \cdot \mathbf{I} \cdot \boldsymbol{t}}{V \cdot \boldsymbol{F}}
$$

239 Many researchers have claimed [38,39] that the use of current densities below $200 \mu \mathrm{A} / \mathrm{cm}^{2}$

240 for accelerated corrosion tests causes a similar (5-10\% difference) loss of weight in the 241 steel to weight loss of bars estimated by Faraday’s law.

242 Thus, it is possible to accurately estimate the corrosion degree achieved by applying 243 electrical current density values below this threshold. Furthermore, current densities above 244 this threshold cause earlier cracking as well as a notable difference with the real corrosion 245 procedure and resulting corrosion products. It is known that the bond between steel and 246 concrete is affected by the corrosion rate [40]. In the present work, 1\% loss of weight of 247 steel bar by corrosion procedure, at ten days was estimated and consequently $130 \mu \mathrm{A} / \mathrm{cm}^{2}$ 
248 of electrical current density was applied. The same electrical current density was also 249 maintained over a period of 20 and 30 days in order to produce $2 \%$ and $3 \%$ of weight loss 250 of steel bar due to the corrosion procedure.

251 In order to produce accelerated corrosion of embedded steel bars by means of impressed 252 current, the steel bars must be depassivated. As previously mentioned in this particular 253 experimental study sodium chloride was added to the concrete mixing water in order to 254 eliminate the passive layer by means of chloride attack.

255 3.3.2 Corrosion procedure

256 The specimens produced in Phase 2 were placed into plastic recipients and approximately $25790 \%$ of their volume immersed $(90 \mathrm{~mm})$ in water, which contained $5 \%$ of $\mathrm{NaCl}$ solution 258 (electrolyte). A copper plate was located under the concrete specimens, see Fig. 4. The 259 copper plate was used as a cathode during the corrosion process, and the steel bar was used 260 as anode. The steel bar and copper plate were connected to the power supply equipment, 261 which provided the specified current as defined earlier. A different number of specimens 262 was connected in series guaranteeing the same intensity (see Fig. 5).

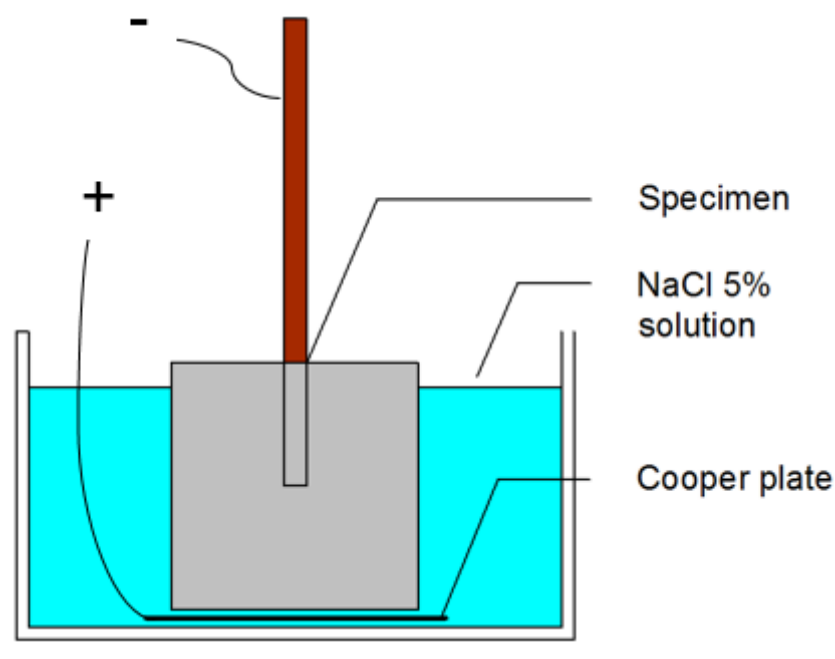

264 Fig. 4. Test setup induced corrosion 

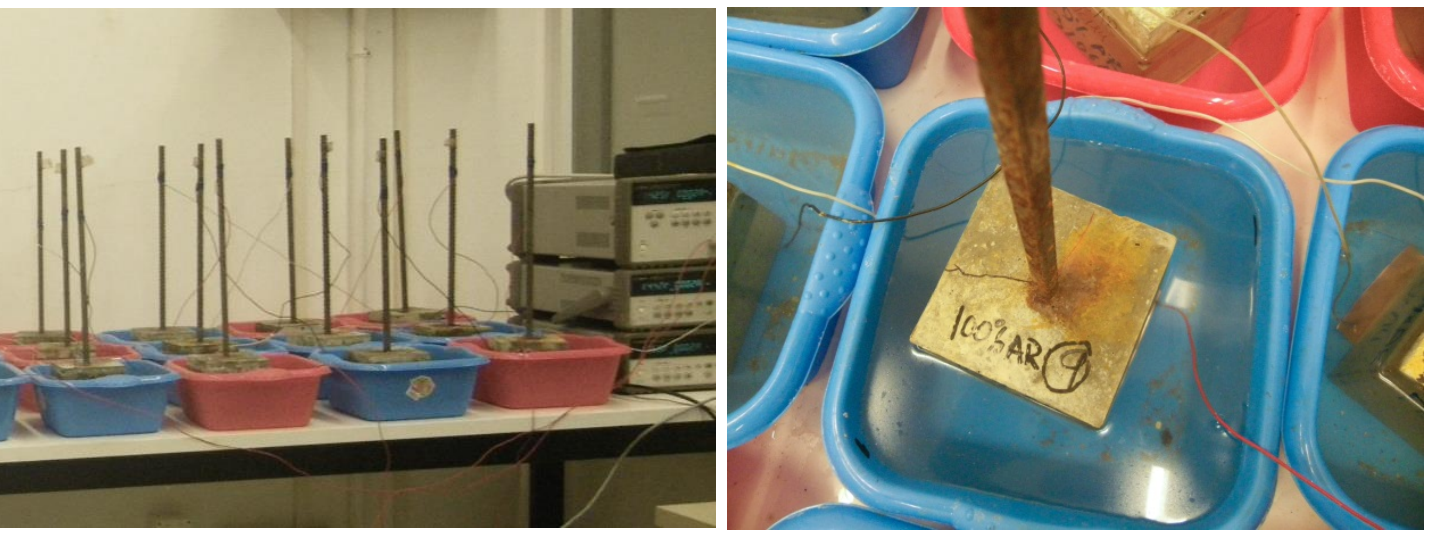

Fig. 5. Series connection scheme for corrosion procedure

267 The instant of the first cracking appearance on the surface of the different types of concrete specimens during corrosion process was evaluated.

269 Three specimens of each type of concrete (CC, RAC-20, RAC-50 and RAC-100) were 270 exposed to the corrosion process at three different ages, 10 days (1\% estimated corrosion

271 degree by Faraday’s law), 20 days (2\% estimated corrosion degree by Faraday’s law) and 27230 days (3\% estimated corrosion degree by Faraday’s law). All the specimens were tested

273 by employing the pull-out test described previously (Phase 2). The percentage of mass loss 274 was measured and compared with the Faraday’s law prediction, in each type of concrete. 275 Chemical cleaning of corroded steel specimens was performed to calculate the steel mass 276 loss, following the specifications [41]. The cleaning procedure was conducted using a 277 solution of hydrochloric acid.

\section{4. Test results}

2794.1 Concrete properties

280 Table 4 describes the compressive strength at 28 days of curing and the standard deviation 281 of the values for all types of concretes produced. 
Table 4. Compressive strength and experimental and theoretical Bond strength $\left(\tau_{\max }\right)$ obtained in phase 1 and phase 2 uncorroded specimens for the four concretes cast

\begin{tabular}{ccccc}
\hline & \multicolumn{2}{c}{$\begin{array}{c}\text { Compressive } \\
\text { strength (MPa) }\end{array}$} & \multicolumn{2}{c}{$\tau_{\max }$-Pull Out test } \\
\cline { 2 - 5 } Concrete Type & Average & Std. & $\begin{array}{c}\text { Phase1 } \\
\text { Exp. }\end{array}$ & $\begin{array}{c}\text { Phase2 } \\
\text { Exp. (un.) }\end{array}$ \\
\cline { 2 - 5 } & 51.2 & 0.92 & 28.64 & 34.36 \\
\hline CC & 48.28 & 0.66 & 29.69 & 35.78 \\
\hline RCA-20 & 47.8 & 0.21 & 27.14 & 32.57 \\
\hline RCA-50 & 49.95 & 3.05 & 30.31 & 35.63 \\
\hline
\end{tabular}

As expected, there was no significant drop in the compressive strength of the RAC 286 specimens with respect to that of CC concrete specimens, due to the adequate compressive 287 strength (40MPa) of the parent concrete. The weak point of medium-high strength 288 concretes made with coarse recycled concrete aggregates can be determined by the strength 289 of the recycled concrete and its attached mortar [18,24]. According to Hansen and Narud 290 [42] the compressive strength of recycled concrete is also strongly correlated with the water 291 -cement ratio of the parent concrete. If the w/c ratio of the parent concrete is the same or 292 lower than that of recycled concrete, the new strength of the recycled concrete will be as 293 good as or better than that of original concrete.

294 In conventional concrete there is only one type of Interfacial Transition Zone (ITZ), i.e., 295 between the natural aggregates and cement paste, while in recycled aggregate concretes 296 there are in fact two: one between the recycled aggregates and the new cement paste and 297 the other (inside recycled aggregate) between the original aggregate and the adhered mortar 298 from the parent concrete. These frontier zones significantly condition the concrete's 299 performance. The failure of recycled aggregate concrete produced employing low strength 
RCA parent concretes occurs in the ITZ between the original aggregates and the adhered

301 mortar or through the adhered mortar of RCA. Contrarily to what happens in recycled 302 aggregate concrete mixed with recycled aggregates from medium-high strength parent 303 concretes. Here the weakest zone is the ITZ between the aggregates (recycled or natural) 304 and the new paste [43], and consequently the compressive strength is not influenced by the 305 adhered mortar. According to Soares et al. [44] the compressive strength of recycled 306 aggregates achieved identical compressive strength to that of conventional concrete, being 307 justified by the shape of the aggregates , their adherence to the cement paste and the quality 308 of the source concrete. Gonzalez and Etxeberria [45] also concluded that recycled 309 aggregate concretes produced employing recycled aggregate from a $100 \mathrm{MPa}$ parent 310 concrete reached identical values to the conventional concrete (around $100 \mathrm{MPa}$ ), even for 311 total aggregates' replacement. However, in all those cases [43-45] it was found that the 312 modulus of elasticity was lower in the recycled aggregate concretes compared to CC 313 concrete. The capacity of the aggregates to resist deformations is controlled by their 314 stiffness and influenced by their porosity. The recycled aggregates are therefore more 315 deformable because of the high porosity of the adhered cement paste.

3164.2 Pull-out test results. Type of concrete influence

\section{4.2.1 Pull-out test results: Phase 1}

318 The results of direct pull-out test in terms of $\tau_{\max }$ (maximum bond capacity) for the 319 specimens produced at Phase 1 are shown in Table 4. As expected the failure mode 320 described was splitting as a consequence of the obtained results of the compressive strength 321 and the c/D ratios employed for the test setup. However, the remaining bond capacity did 322 not drop to zero after the failure took place. The value of $\tau_{\max }$ was very similar in all the 
concretes with lower than $10 \%$ variation with respect to the maximum bond capacity of

324 CC. That variation was in accordance with the compressive strength obtained by RAC and 325 CC concretes, as already reported by other researchers [10,46].

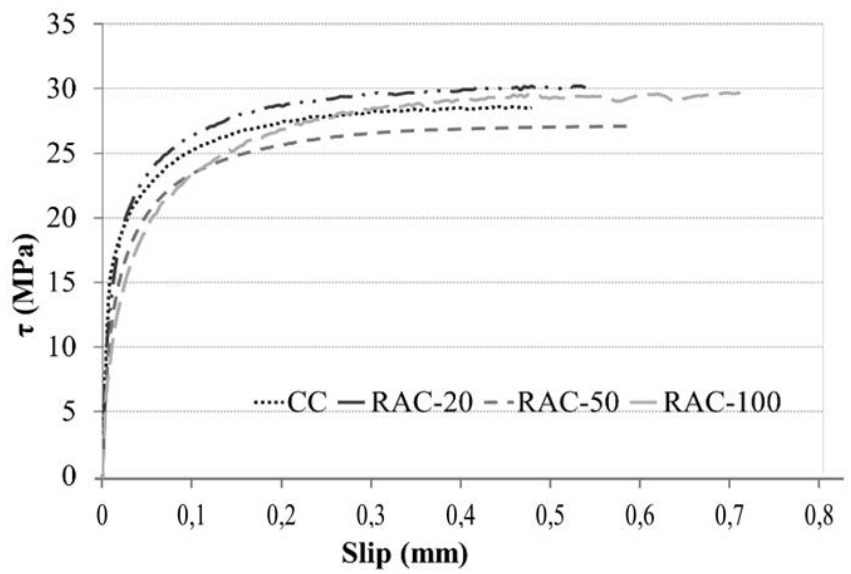

327 Fig. 6. Direct bond $\tau$ (MPa)-slip (mm) curves of the four types of concrete

328 The LVDT placed underneath the specimen was able to monitor and register the actual 329 direct slip between the concrete and steel bar. Fig. 6 shows the direct bond-slip curves of 330 the four types of concretes. It shows that the maximum slip registered was higher in RAC 331 concretes, and it increased when higher percentages of recycled aggregates were used. Fig. 3327 illustrates the pull-out test of CC concrete.

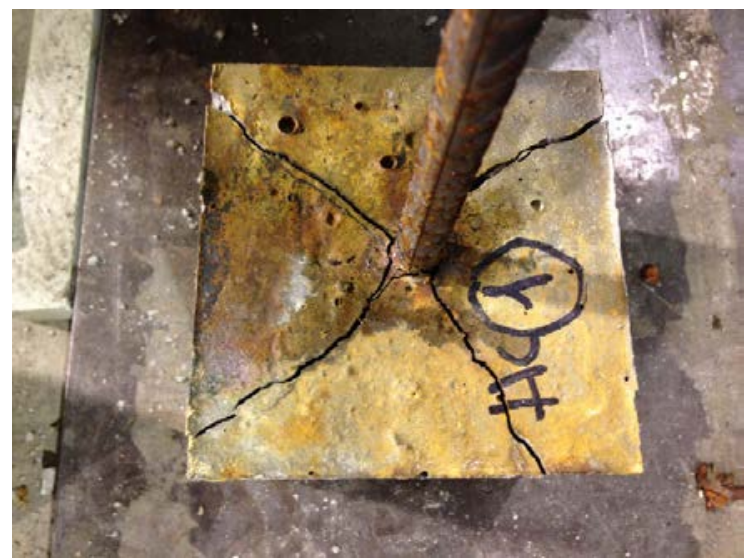

\section{Fig. 7. Specimen after pull-out test}


335 Fig. 8 shows the average values of the instant $\tau$ with respect to the $\tau_{\text {max }}$ ratio for each type

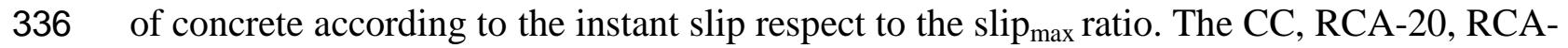
33750 concretes showed almost the same stiffness with smooth variations in the curves. 338 However, RCA-100 presented higher slips for the same $\tau_{\max }$. There was a considerable 339 reduction in stiffness, more than $30 \%$, in the RAC-100 concrete when compared to other 340 concretes. A behaviour fact which has also been documented by other authors [14]. It is 341 also known that the modulus of elasticity is reduced with the employment of RCA for 342 concrete production [20,24] and it is coherent with the behaviour observed in Fig. 6 and 8. 343 The higher porosity registered for RCA concretes could correctly explain this behaviour in 344 concretes produced with $100 \%$ of RCA.

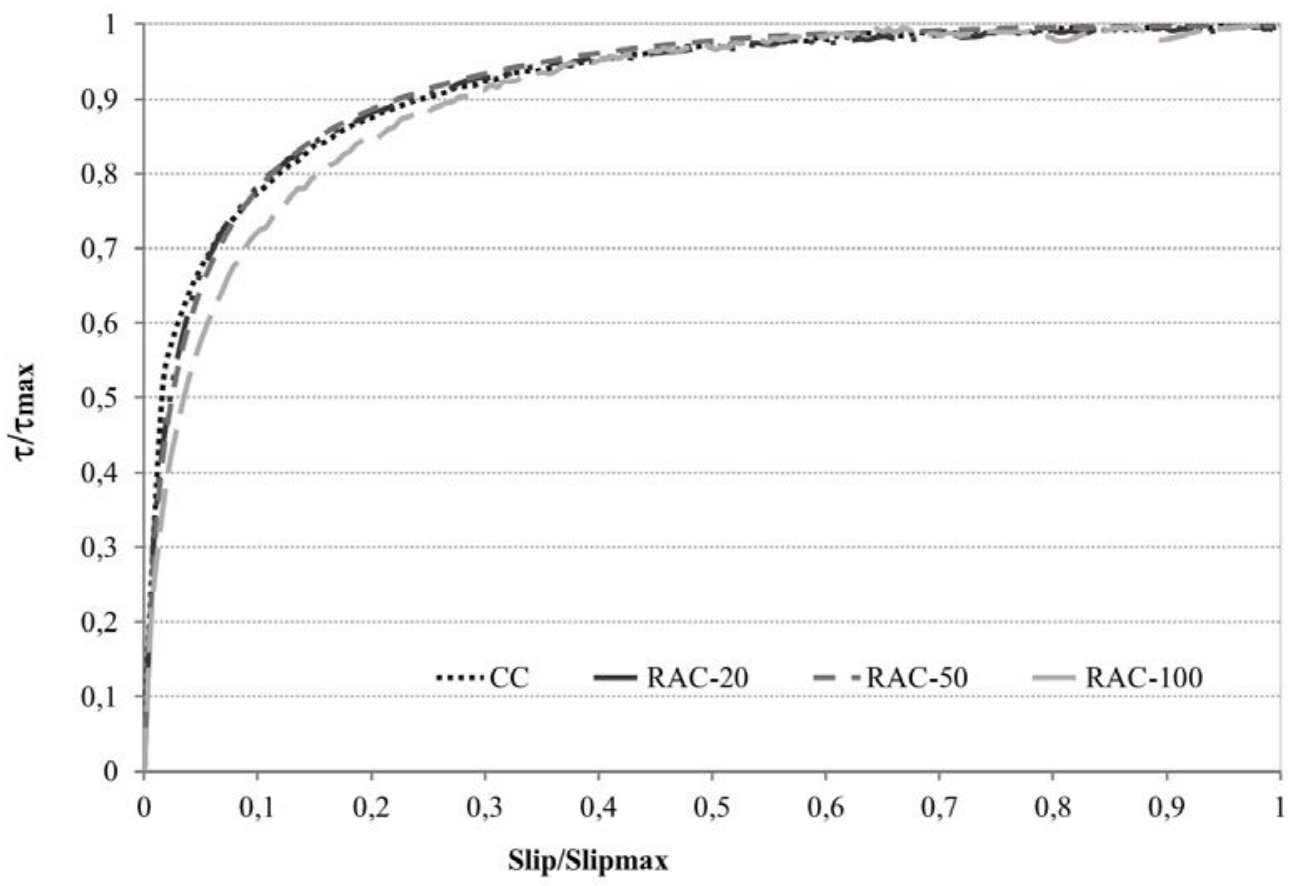


349 The $\tau_{\max }$ value for the four types of concrete specimens, with uncorroded bars, are shown in

350 Table 4. The $\tau_{\max }$ value for recycled aggregate concretes was similar to that obtained for

351 CC concrete. RAC-20 concrete presented a slightly higher $\tau_{\max }$, when RAC-50 suffered a

352 lower reduction than $10 \%$ with respect to the value of conventional concrete. The RCA-100

353 obtained a similar value to that of CC concrete. These values were in accordance with those

354 obtained in Phase 1 and also in accordance with similar compressive strength results

355 obtained by all the concretes. As mentioned by some researchers $[47,48]$ the bond between

356 reinforcing steel and concrete depends on the geometric properties of both steel and

357 concrete as well as of the concrete properties. Regarding concrete properties, its

358 compressive strength is stated as the most important parameter. Kim and Yun [47]

359 confirmed that the compressive strength was also the adequate parameter to be used for

360 bond strength characterization for concretes produced employing fine recycled aggregates.

361 4.2.3 Discussion

362 Fig. 9 shows the ratio between the $\tau_{\max }$ (Phase 1), $\tau_{\max }$ (Phase 2) and the compressive 363 strength for the three RA concretes produced with respect to the same values of CC 364 concrete. As illustrated, the results obtained by recycled aggregate concretes were similar 365 to those obtained by conventional concrete. The $\tau_{\max }$ value for recycled aggregate concretes 366 reached or exceeded that of conventional concretes except for the concrete produced with $36750 \%$ of recycled aggregates. In all cases, all the registered variations were attributed to the 368 inherent high dispersion of the pull-out tests [37]. 


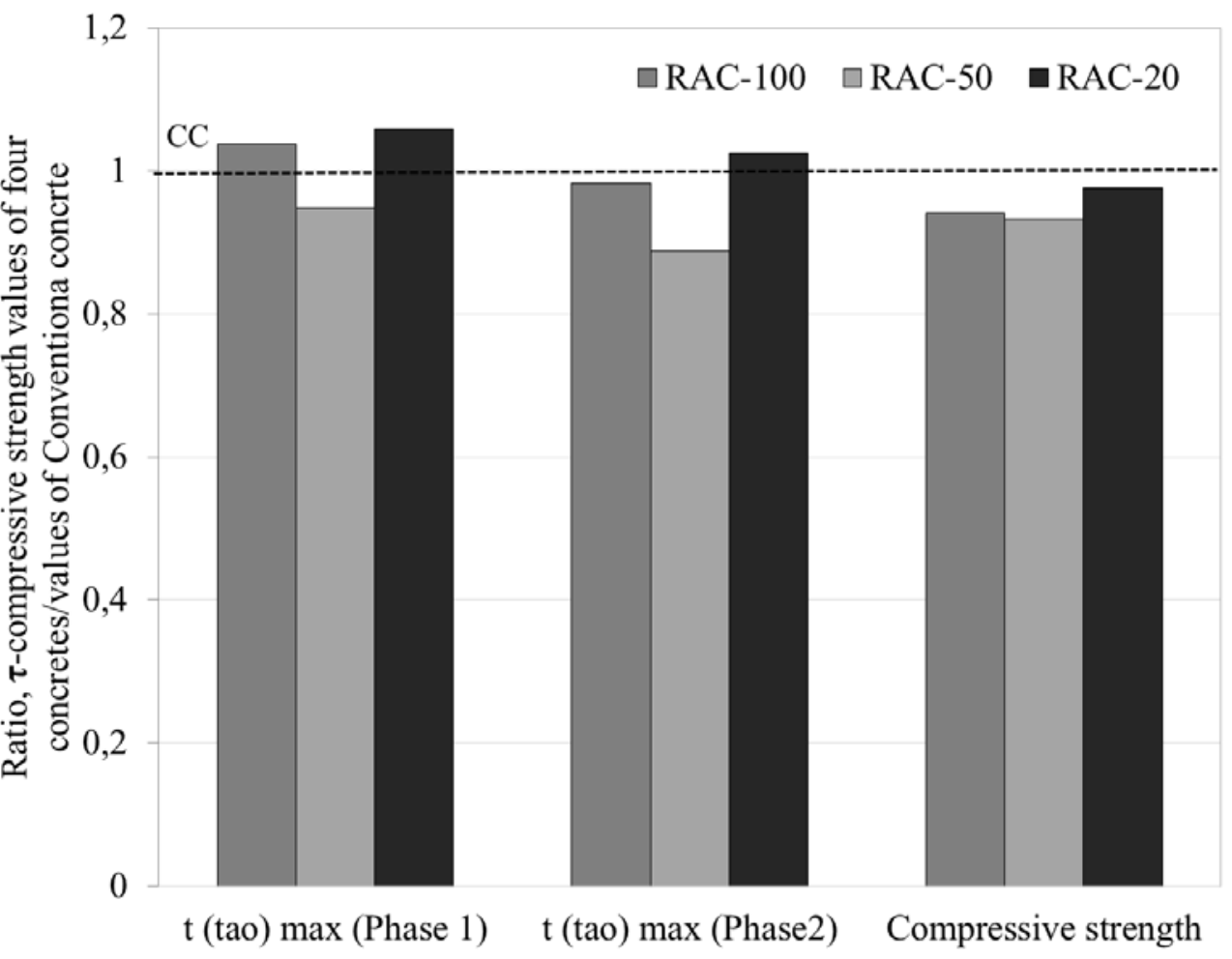

Fig. 9. Ratio of $\tau_{\max }$ (phase 1), $\tau_{\max }$ (phase2) and compressive strength of all the concrete

371 produced with respect to the same values of conventional concrete.

372 Fig. 10 shows the influence of compressive strength on $\tau_{\max }$ values, determined by the ratio

373 of $\tau_{\text {max-RAC }} / \tau_{\text {max-CC }}$ with respect to $\mathrm{f}_{\mathrm{c}-\mathrm{RAC}} / \mathrm{f}_{\mathrm{c}-\mathrm{CC}}$. All the values were approximately one, due to 374 the similar compressive strength of all the concretes studied and its influence on bond 375 strength determination in any type of concretes. Similar conclusions were obtained by other 376 researchers [47-49]. 


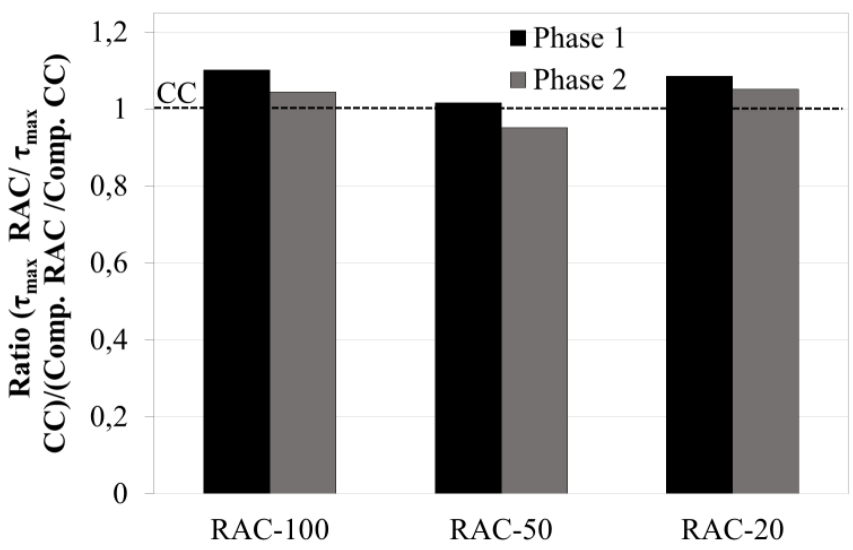

Fig. 10. Ratio of $\tau_{\max -\mathrm{RAC}} / \tau_{\max -\mathrm{CC}}$ with respect to $\mathbf{f}_{\mathrm{c}-\mathrm{RAC}} / \mathbf{f}_{\mathrm{c}-\mathrm{CC}}$.

4.3 Phase 2 results. Corrosion degree influence

\subsubsection{Weight loss determination}

381 Table 5 shows the resulting mass loss for each specimen and the average weight loss of all 382 bars at different exposition time. The weight loss obtained experimentally was a little 383 higher than that determined by Faraday’s law at 10 day and 20 days of exposure. However, 384 at 30 days of exposure the real mass loss was higher, probably due to the influence of 385 concrete cracking in the accelerating of corrosion process. In any case as described in 386 Maadaway et al. [38], experimental results of the accelerated corrosion method always 387 produced higher mass loss than the theoretical estimation. Fig. 11 demonstrates the steel 388 bars before and after the cleaning was performed. 
Table 5. Determined corrosion levels by mass loss.

\begin{tabular}{|c|c|c|c|c|c|c|}
\hline \multirow{2}{*}{$\begin{array}{l}\text { Type of } \\
\text { concrete }\end{array}$} & \multicolumn{2}{|c|}{$\begin{array}{l}10 \text { exposition days } \\
\text { (1\% mass loss according } \\
\text { to Faraday’s law }\end{array}$} & \multicolumn{2}{|c|}{$\begin{array}{c}20 \text { exposition days } \\
\text { (2\% mass loss according } \\
\text { to Faraday's law) }\end{array}$} & \multicolumn{2}{|c|}{$\begin{array}{c}30 \text { exposition days } \\
\text { (3\% mass loss according } \\
\text { to Faraday’s law) }\end{array}$} \\
\hline & $\begin{array}{l}\text { Corrosion } \\
\text { level (\%) }\end{array}$ & $\begin{array}{c}\text { Average } \\
(\%)\end{array}$ & $\begin{array}{l}\text { Corrosion } \\
\text { level (\%) }\end{array}$ & Average (\%) & $\begin{array}{l}\text { Corrosion } \\
\text { level (\%) }\end{array}$ & $\begin{array}{c}\text { Average } \\
\text { (\%) }\end{array}$ \\
\hline \multirow{3}{*}{$\mathrm{CC}$} & -- & \multirow{14}{*}{1.65} & 1.86 & \multirow{14}{*}{2.6} & 5.71 & \multirow{14}{*}{5.75} \\
\hline & -- & & 1.89 & & 6.59 & \\
\hline & -- & & 2.18 & & 5.65 & \\
\hline \multirow{4}{*}{ RAC-20 } & 1.66 & & 2.42 & & 5.40 & \\
\hline & 0.83 & & 2.54 & & 5.75 & \\
\hline & 1.58 & & 2.40 & & 4.99 & \\
\hline & & & 2.61 & & & \\
\hline \multirow{3}{*}{ RAC-50 } & 1.35 & & 3.16 & & 5.94 & \\
\hline & 1.86 & & 2.24 & & 6.65 & \\
\hline & 1.93 & & 3.28 & & 5.02 & \\
\hline \multirow{4}{*}{ RAC-100 } & 2.23 & & 2.91 & & 6.35 & \\
\hline & 1.69 & & 3.04 & & 5.43 & \\
\hline & 1.70 & & 3.04 & & 5.60 & \\
\hline & & & 2.87 & & & \\
\hline
\end{tabular}



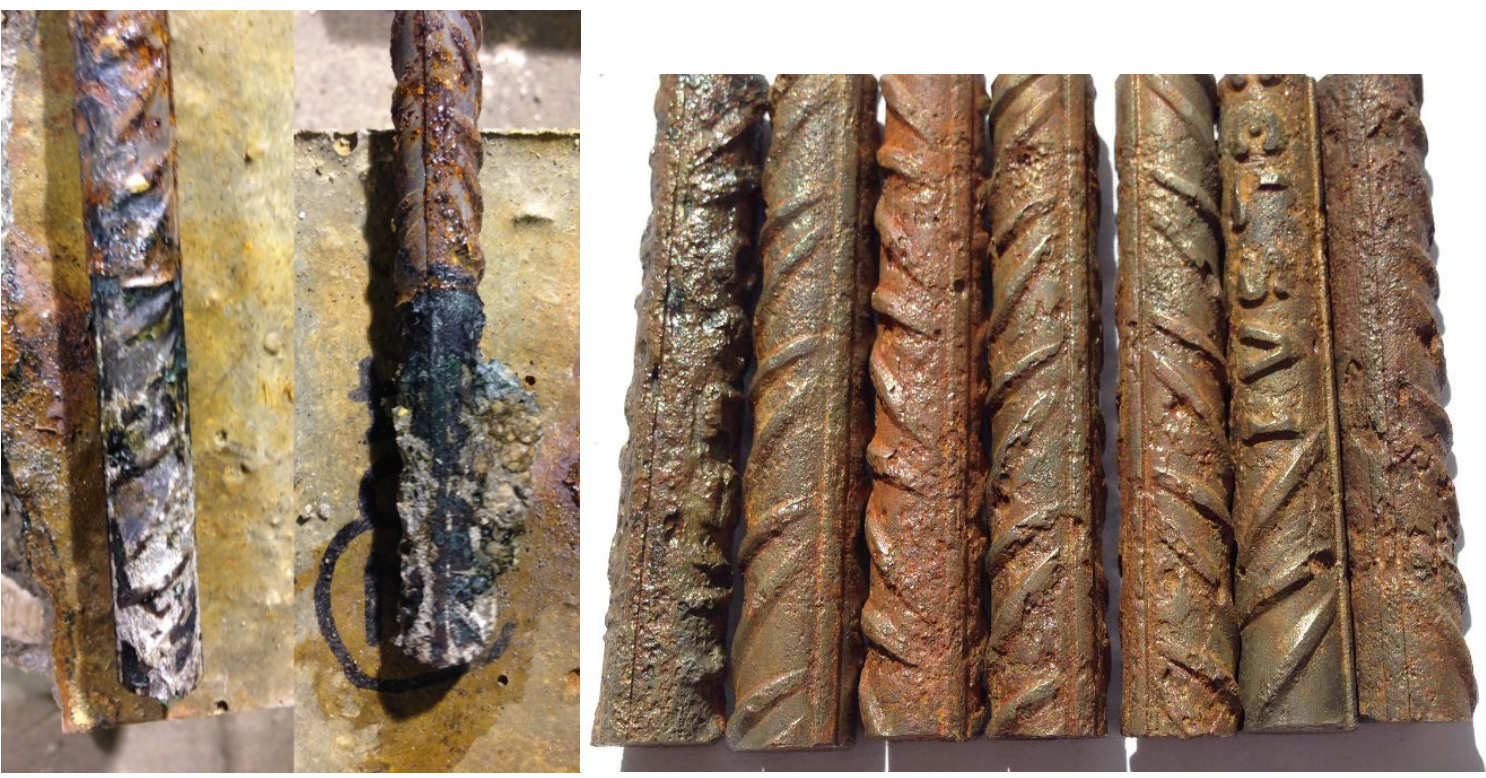

Fig. 11. Steel bar specimens before and after cleaning procedure

\subsubsection{Surface cracking due to corrosion procedure}

Cracks produced by corrosion are a major problem during the concrete deterioration process. The instant of the first surface cracking of each type of concrete during the electrical current exposition period was determined (see Table 6).

Table 6. Description of the exact time of the first cracking of each type of concrete and the ratio of required time by each RAC concretes with respect to that of $\mathrm{CC}$ in percentage

\begin{tabular}{lcccc} 
Concrete type & CC & RAC-20 & RAC-50 & RAC-100 \\
\hline $\begin{array}{l}\text { First cracking time (in } \\
\text { days) }\end{array}$ & 4.75 & 6.15 & 7.66 & 6.55 \\
$\begin{array}{l}\text { Ratio of required time } \\
(\%)\end{array}$ & 0 & 29.47 & 61.26 & 37.89 \\
\hline
\end{tabular}

405 It was noted that the RAC concrete needed approximately 30\% more exposure time than

406 conventional concrete for the first surface cracking to appear. According to Yalciner et al.

407 [33] the concretes produced with high water/cement ratio needed more time for the first 408 outer cracking than concretes with low water/cement ratio. This being due to the lower 
409 porosity of later ones. The high porosity of concrete had similar adequate influence on the

410 occurrence of the first cracking in all tested concretes. In this research work the higher

411 porosity of the recycled aggregates, which had a greater capacity for absorbing the internal

412 stresses caused by the corrosion products, delayed the surface cracking. A higher corrosion

413 degree was needed in order to achieve the same external cracking for RAC.

414 Table 7. Description of surface cracking pattern caused by corrosion cracking

\begin{tabular}{|c|c|c|c|c|c|c|c|c|c|}
\hline \multirow[t]{2}{*}{$\begin{array}{l}\text { Concrete } \\
\text { type }\end{array}$} & \multirow{2}{*}{$\begin{array}{l}\text { Estimated } \\
\text { corrosion } \\
\text { level }\end{array}$} & \multirow[t]{2}{*}{$\begin{array}{l}\text { External } \\
\text { Crack } \\
\text { amount }\end{array}$} & \multicolumn{3}{|c|}{$\begin{array}{c}\text { Numeration of cracks } \\
\text { on upper face } \\
\text { (cms) }\end{array}$} & \multicolumn{3}{|c|}{$\begin{array}{l}\text { Numeration of Crack on } \\
\text { lateral faces }(\mathrm{cms})\end{array}$} & \multirow[t]{2}{*}{$\begin{array}{c}\tau_{\max } \\
(\mathrm{MPa})\end{array}$} \\
\hline & & & 1 & 2 & 3 & 1 & 2 & 3 & \\
\hline \multirow{7}{*}{ CC } & \multirow{2}{*}{$1 \%$} & 3 & 6.0 & 5.0 & 4.5 & - & 3.0 & 5.5 & 5.53 \\
\hline & & 3 & 3.0 & 5.0 & 5.0 & - & 4.0 & 6.5 & 5.47 \\
\hline & \multirow{2}{*}{$2 \%$} & 3 & 6.0 & 5.0 & 4.5 & - & 3.0 & 5.5 & 4.09 \\
\hline & & 3 & 3.0 & 5.0 & 5.0 & - & 4.0 & 6.5 & 5.37 \\
\hline & \multirow{3}{*}{$3 \%$} & 2 & 4.5 & 4.5 & - & 8.0 & 9.0 & - & 3.47 \\
\hline & & 2 & 4.0 & 4.5 & - & 9.0 & 8.5 & - & 4.13 \\
\hline & & 3 & 4.0 & 4.5 & 4.0 & 10.0 & 8.5 & 5.5 & 4.39 \\
\hline \multirow{8}{*}{ RAC-20 } & \multirow{2}{*}{$1 \%$} & 3 & 2.5 & 5.5 & 4.5 & - & - & 2.0 & 6.72 \\
\hline & & 2 & 4.4 & 4.5 & - & 1.0 & 5.5 & - & 7.13 \\
\hline & \multirow{4}{*}{$2 \%$} & 2 & 4.0 & 4.5 & & 7.0 & 5.0 & & 6.61 \\
\hline & & 3 & 5.0 & 4.5 & 5.0 & 5.0 & 6.5 & 7.0 & 4.92 \\
\hline & & 3 & 6.0 & 5.0 & 4.0 & 4.5 & 3.5 & 8.0 & 5.28 \\
\hline & & 2 & 4.5 & 4.5 & - & 4.0 & 7.0 & - & 5.81 \\
\hline & \multirow{2}{*}{$3 \%$} & 2 & 5.0 & 4.0 & - & 7.5 & 3.0 & - & 5.31 \\
\hline & & 2 & 5.0 & 4.5 & - & 5.5 & 6.0 & - & 4.32 \\
\hline \multirow{7}{*}{ RAC-50 } & \multirow{2}{*}{$1 \%$} & 1 & 7.0 & - & - & - & - & - & 6.91 \\
\hline & & 2 & 4.0 & 4.0 & - & 1.5 & 6.0 & - & 6.24 \\
\hline & \multirow{3}{*}{$2 \%$} & 3 & 4.0 & 5.5 & 6.0 & 4.0 & 5.0 & - & 5.20 \\
\hline & & 3 & 4.5 & 4.5 & 4.0 & 8.0 & 1.0 & 9.5 & 5.65 \\
\hline & & 3 & 5.0 & 4.5 & 5.0 & 8.0 & 8.0 & 6.0 & 6.30 \\
\hline & \multirow{2}{*}{$3 \%$} & 1 & 5.5 & - & - & 6.0 & - & - & 5.04 \\
\hline & & 1 & 4.5 & - & - & 8.5 & - & - & 3.53 \\
\hline \multirow{7}{*}{ RAC-100 } & \multirow{2}{*}{$1 \%$} & 3 & 4.7 & 4.0 & 4.0 & - & - & - & 8.40 \\
\hline & & 2 & 5.5 & 4.0 & - & 5.5 & 5.5 & - & 7.67 \\
\hline & \multirow{3}{*}{$2 \%$} & 3 & 4.0 & 4.5 & 5.0 & 3.0 & 8.0 & 4.5 & 6.58 \\
\hline & & 3 & 4.2 & 5.5 & 4.0 & 1.0 & 4.0 & 4.5 & 6.30 \\
\hline & & 3 & 6.0 & 5.5 & 4.5 & 4.5 & 6.5 & 8.0 & 5.49 \\
\hline & \multirow{2}{*}{$3 \%$} & 2 & 4.5 & 4.5 & - & 7.0 & 9.0 & - & 3.90 \\
\hline & & 3 & 4.0 & 6.5 & 6.0 & 8.5 & 6.0 & 6.0 & 4.50 \\
\hline
\end{tabular}


416 A description of surface crack pattern caused by corrosion cracking is described in Table 7 417 (Fig. 12 illustrates the cracking of CC and RAC-100 at $1.6 \%$ and $5.75 \%$ of corrosion 418 degree). The first outer cracks appeared on the upper face of the concrete cubic specimens, 419 in which the steel bar was embedded. The cracks became prolonged on the lateral faces due 420 to the increase of corrosion degree. Table 7 describes the total amount of cracks that 421 appeared: the enumeration of the upper face cracks represents the order of occurrence, 422 whilst the lateral face crack's enumeration corresponds to the number of the upper face 423 crack prolongation. The $\tau_{\max }$ of all the corroded samples is also described in the same Table 4247.

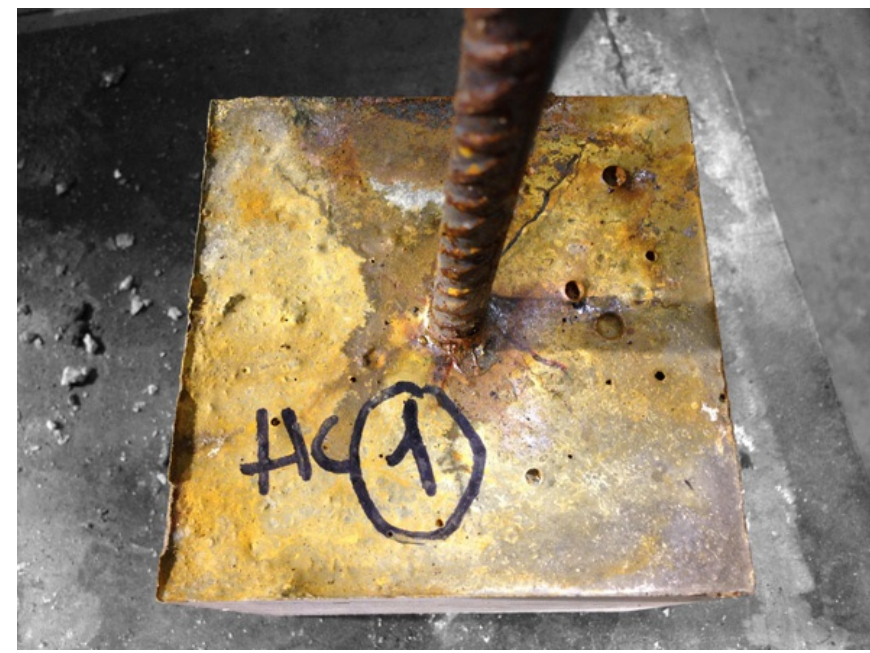

(a) CC concrete at $1.6 \%$ corrosion degree

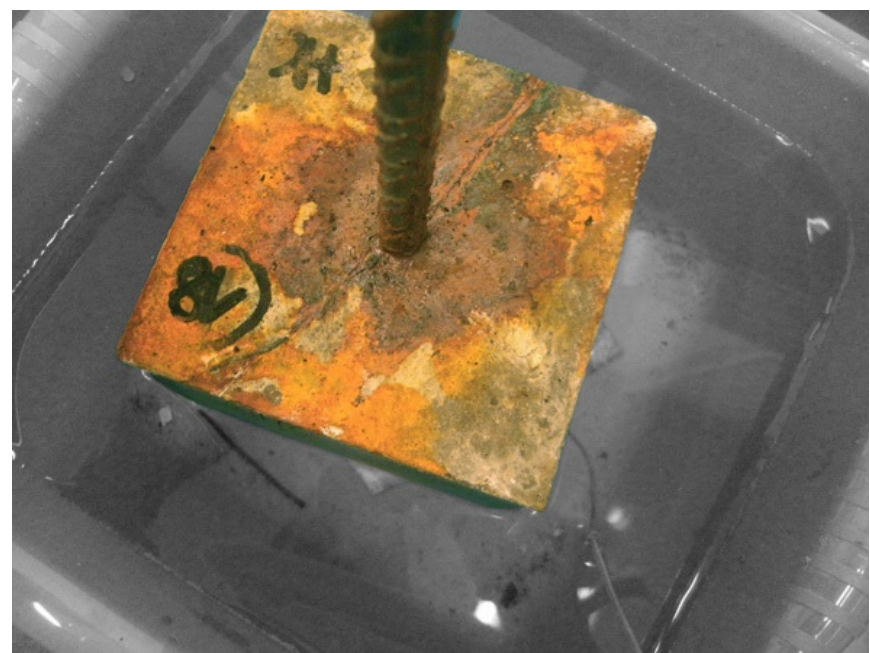

(b) CC concrete at $5.75 \%$ corrosion degree 


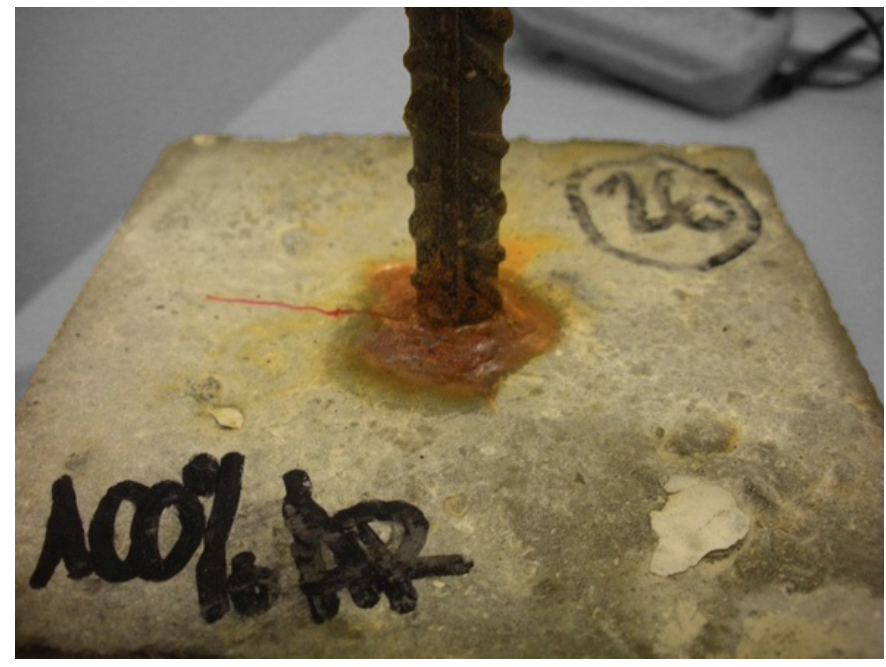

(c) RAC-100 concrete at $1.6 \%$ corrosion degree

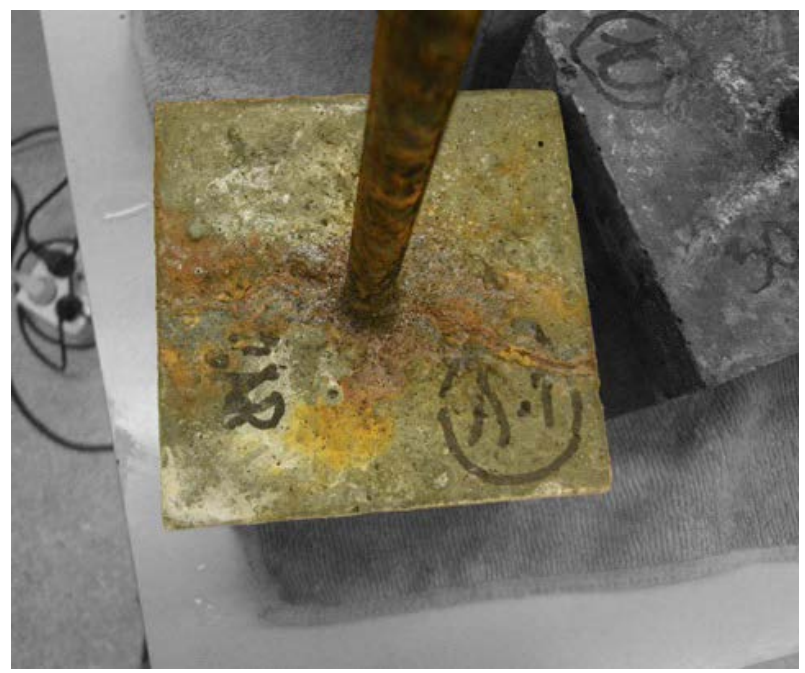

(d) RAC-100 concrete at $5.75 \%$ corrosion degree

Fig. 12. Cracking of different specimens after corrosion exposition

427 It must be considered as remarkable that there was no clear relationship between the values

428 obtained by the visual crack measurements and the $\tau_{\max }$ achieved for each concrete by

429 means of the direct pull-out tests (Phase 2). A similar behaviour was stated by Yalciner et

430 al. [33], where the bond strength capacity was not attributed to the number of cracks in

431 conventional concretes. That phenomenon could most probably be attributed to the

432 different internal damage on each specimen. Due to the impossibility of observing the

433 internal damage via a visual inspection a post pull-out test examination was performed on

434 the samples. 

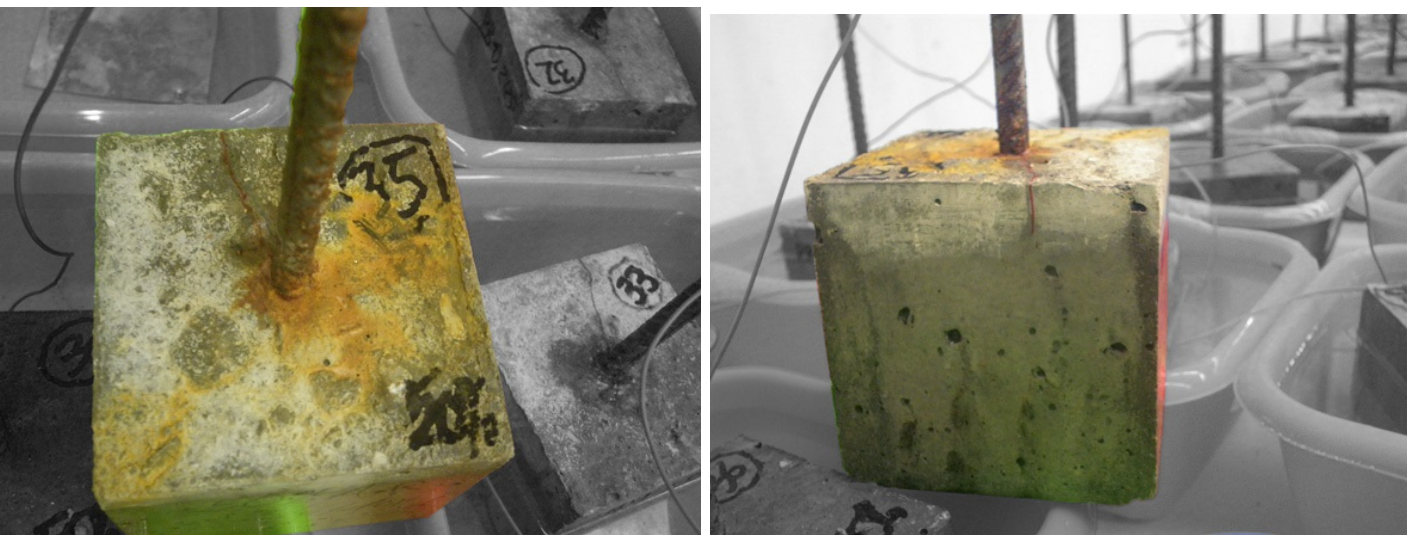

Fig. 13. Surface cracking of RAC-50 at 5.75\% of corrosión degree.

438 Nearly all the samples showed 2 or 3 upper surface cracks which later became prolonged 439 on the lateral faces. However, with respect to the RAC-50 concrete it was noted that after 44030 days of being induced by electrical current (of $130 \mu \mathrm{A} / \mathrm{cm}^{2}$ ) it only suffered one crack 441 on its upper surface, which later became prolonged on one of the lateral faces (see Fig. 13).

442 However, in accordance with the above-mentioned hypothesis, the pull-out test revealed 443 severe internal damage. The corrosion products could fill the pores of concrete producing 444 stress and changing the crack pattern. Consequently, specimens could not release those 445 products causing internal damage. Fig. 14 depicts other specimens with differing forms of 446 internal damage, revealing different internal crack formations.

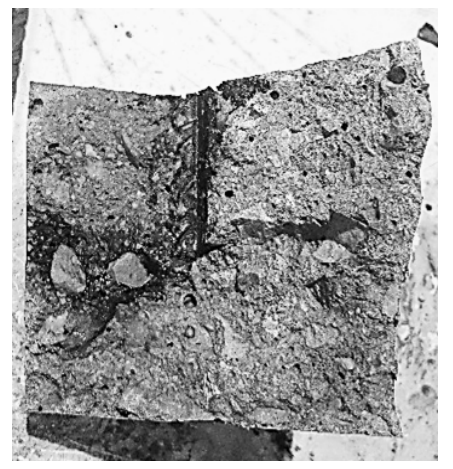

448 Fig. 14. Internal damage cracking for RAC-50 
451 Table 8 describes the results of the pull-out tests ( $\tau_{\max }$ and its standard deviation) carried 452 out with uncorroded (0\% corrosion degree) and corroded steel bars (with 1.6\%, 2.6\% and $4535.75 \%$ corrosion degree). As previously mentioned, CC concrete and RAC concretes had 454 similar bond strength when they were not exposed to the corrosion effect.

455 At the different degrees of the steel bar corrosion (1.65\%, 2.60\% and 5.75\%), the bond 456 strength for all RAC specimens was higher than that of the CC concrete. In addition, this 457 difference increased when a larger amount of RCA was employed in concrete production. 458 Consequently, the concretes produced with a large amount of RCA presented better 459 behaviour in terms of bond capacity under corrosion. Nevertheless, this better response 460 significantly decreased as the specimen became more corroded, achieving roughly similar $461 \tau_{\max }$ values after $5.75 \%$ of degree of corrosion.

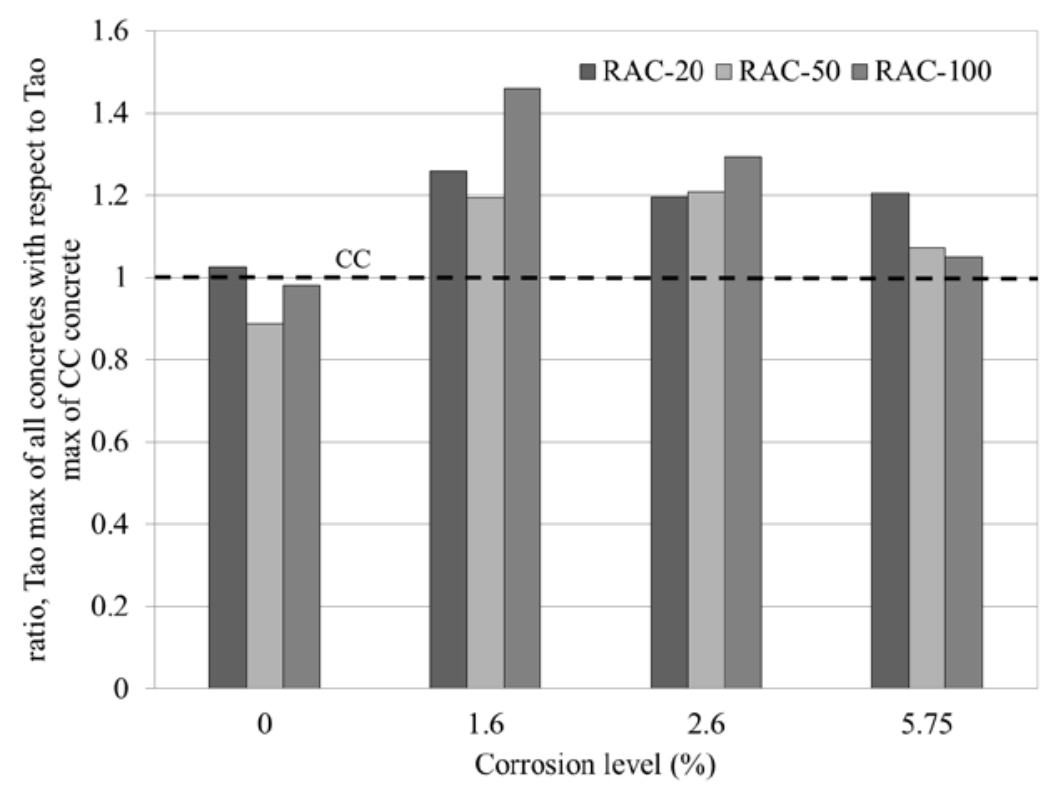

463 Fig. 15. Ratio of $\boldsymbol{\tau}_{\max }$ (phase2) of all the concrete produced with respect to that value of 464 conventional concrete at different corrosion degree (\%) . 
465 Fig. 15 shows the ratio of the $\tau_{\max }$ of the recycled aggregate concretes with respect to that 466 of the conventional concrete at different corrosion degrees. It can be observed that the $\tau_{\max }$ 467 was higher in all of the RAC concretes than in the CC, independent of the percentages of 468 recycled aggregates used for concrete production and the corrosion degree of the steel bars.

469 Although an improvement of the bond capacity in RAC was observed at all the tested 470 corrosion levels, that improvement was found to be almost negligible for higher corrosion 471 levels.

mesured corrosion degree

$1.65 \%$

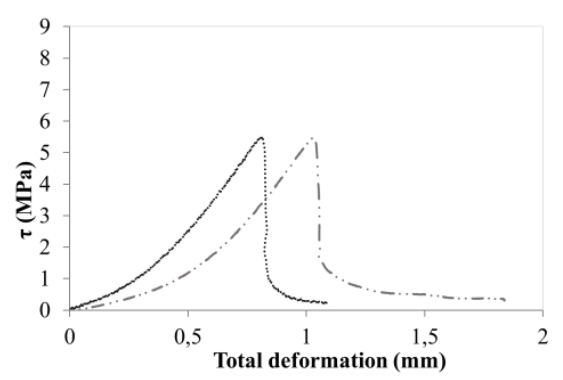

RAC-

20

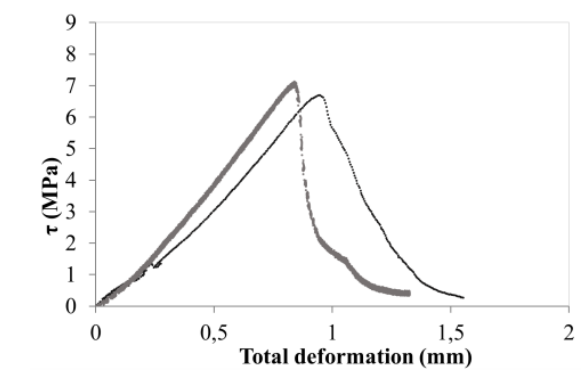

RAC50
$2.60 \%$
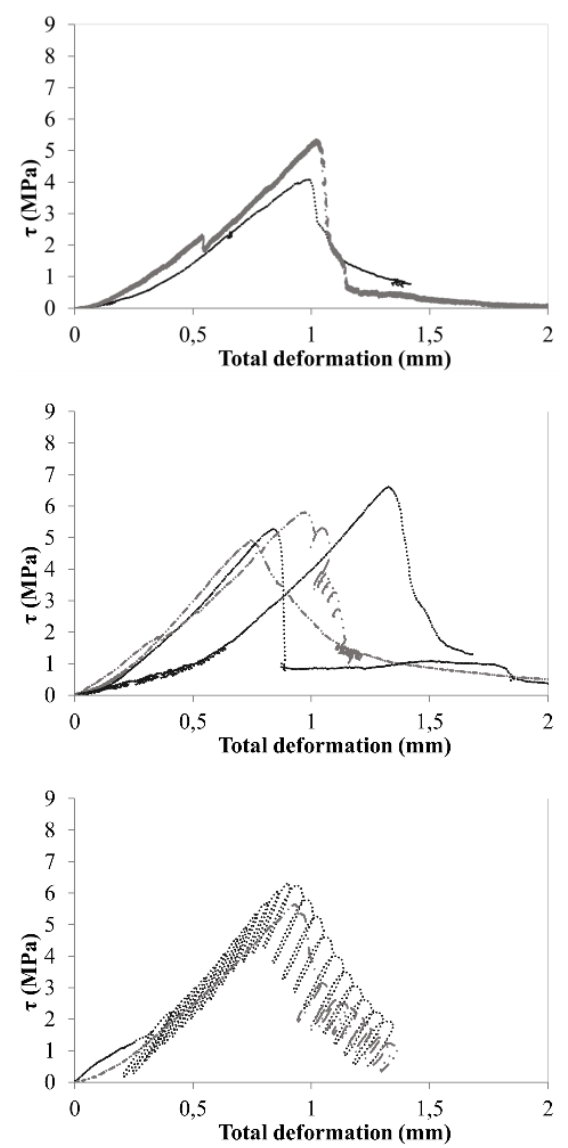

$5.75 \%$
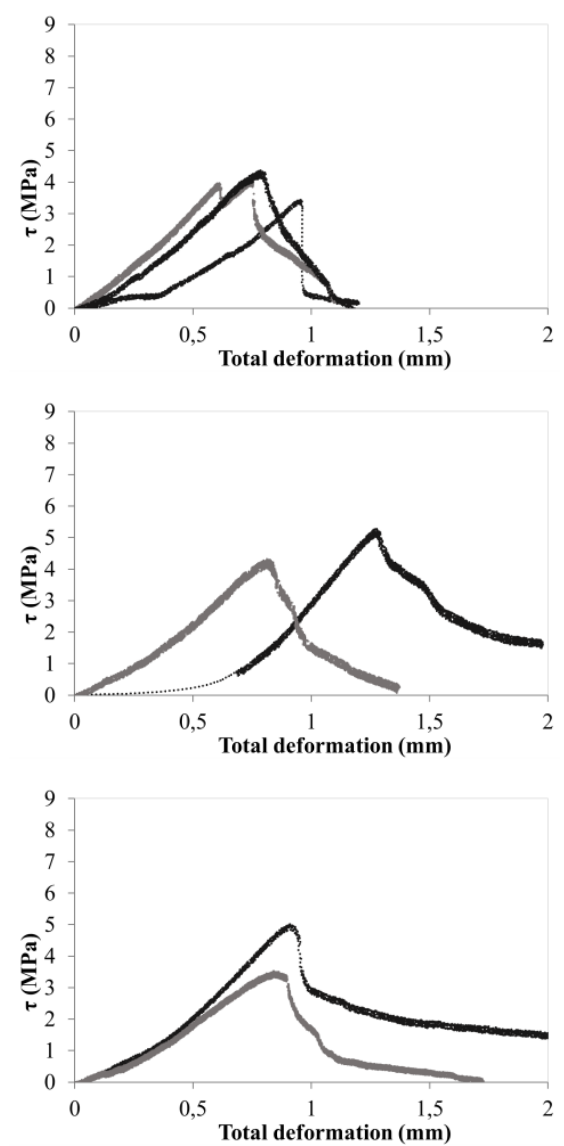
RAC-
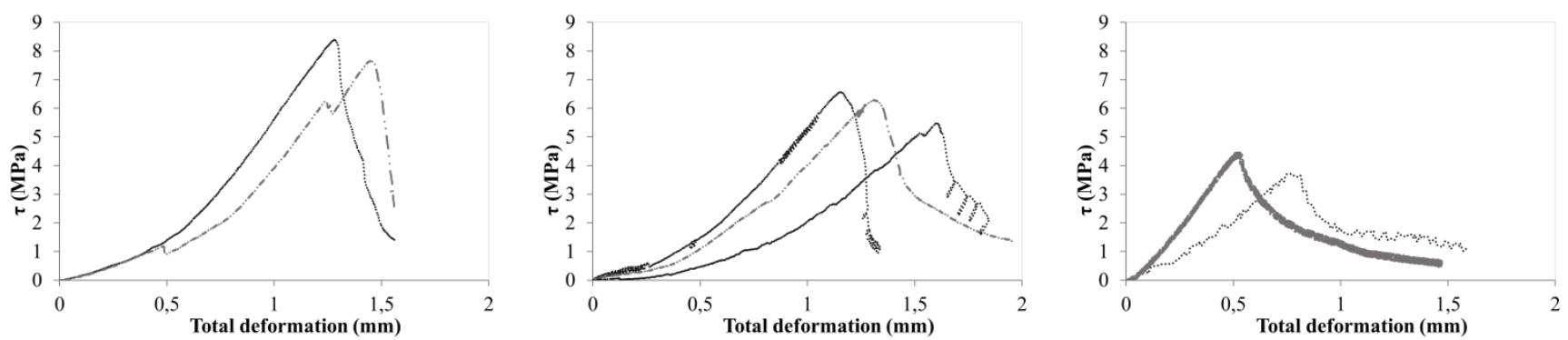

Fig. 16. Bond ( $\tau$, MPa) -displacement $(\mathrm{mm})$ behaviour of all the tested corroded specimens

Fig. 16 describes the bond-displacement behaviour of all the tested corroded specimens (2-

4754 samples were used in each type of concretes). As mentioned, the displacement showed

476 corresponds to a total displacement which includes slip in the clamps, free steel bar length

477 deformation, etc., as well as the slip between both materials. This is due to the

478 configuration of the pull-out test in Phase 2. However, it is possible to observe the

479 specimen's general behaviour in terms of $\tau$-displacement. The concretes produced

480 employing a higher amount of RCA suffered a higher total deformation, in accordance with

481 the results described in Phase 1, where the RCA-100 showed a stiffer bond-slip behaviour

482 than the other specimens.

483 The increase of the bond strength of the RAC concrete occurred while there was a very low

484 degree of corrosion. This was probably due to the confinement effect cause by the

485 expanded corrosion product between bars and concrete. According to other researchers

486 [49-51] slight corrosion of the steel improves the bond strength due to the increase in steel

487 bar surface roughness or friction. Furthermore, the higher porosity of CC concrete [33] and

488 consequently of RAC reduced the stress level in the surrounding concrete (due to its

489 absorption capacity of that product) increasing the bond strength. However, for high 
corrosion degrees, the absorption capacity of those concretes has no influence on the cause

491 of a significant bond strength reduction as was described in this study.

\subsection{Ultimate bond strength ( $\left.\tau_{\max }\right)$ estimation models}

493 There are few mathematical models in the literature upon the subject which estimate/ 494 predict the bond strength value for CC [33,52] and as expected much fewer models 495 designed to determine the bond strength for RAC concretes [11,13].

496 In accordance with the bond strength prediction of CC concrete, the values obtained by 497 Model Code [52] depend on the compressive strength of the concrete. The model defined 498 by Yalciner et al. [33] takes into account the compressive strength of concrete and the ratio 499 between the concrete cover and steel bar diameter for the pull-out test setup. The model 500 defined by Kim \&Yun [11] for RAC concretes, takes into account the compressive strength

501 of conventional concrete, the ratio between the concrete cover and steel bar diameter for 502 pull-out test setup and the influence of a percentage of RCA in the concrete.

503 Fig. 17 shows the estimated bond strength values of the four types of concretes according to 504 the three mathematical models described previously, defined by Kim \&Yun [11], Model 505 Code [52], and the model defined by Yalciner et al. [33]. The bond strength values 506 predicted by Kim \& Yun model [9] underestimated the real experimental values obtained 507 by recycled aggregates concretes as it considers the compressive strength of RAC to be 508 lower than that of conventional concrete due to the presence of RCA which consequently 509 also effects the bond strength. 

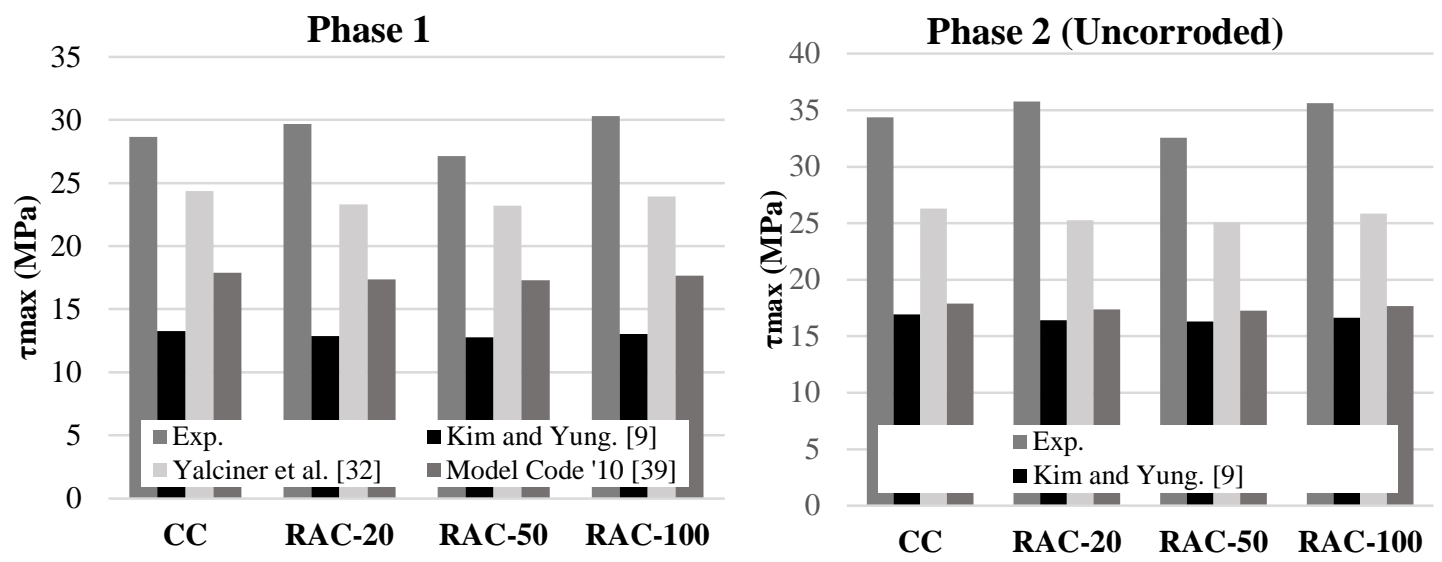

Fig. 17. Phase 1 and Phase 2 experimental and numerical bond strength values.

512 However, of all three model, the model defined by Yalciner et al. [33], predicts more

513 adequately the bond strength of all the concretes. It considers that the prediction of the bond

514 strength of any concrete depends only on its compressive strength values and the ratio

515 between the concrete cover and steel bar diameter for the pull-out test. It does not take into

516 account the influence of a different percentage of RCA. The models defined for the

517 prediction of the bond strength of CC concretes could be employed to adequately predict

518 the bond strength of recycled aggregate concrete when those RAC concretes are produced

519 with the similar compressive strength of the parent concrete of RCA. The Model Code [52]

520 underestimated the bond strength of both types of RAC and CC concretes as it only

521 considered the compressive strength of concrete as input.

522 Yalciner et al. [32] proposed an analytical model for the determining of bond strenth

523 between concrete and the different degrees of corroded reinforcing steel. That model

524 could be employed when the ratio cover/diameter (c/D) is between 1 and 3.2. It must be

525 noted that the ratio c/D for the tested specimens is 4.5, which is outside the bounds defined

526 in the model. Fig. 18 shows the obtained results in this research work in comparison to the 
527 values calculated by the mentioned model. According to the obtained results, the model 528 overestimated the results achieved by the four types of concretes at low corrosion degrees 529 except for concretes produced employing 100\% of recycled aggregates, which was 530 adequately predicted at low degrees of corrosion. The model also adequately predicted the 531 behaviour of all the concretes at 5.75\% corrosion degree. The trend described for both the 532 experimental data and the numerical data was very similar. However, the real behaviour 533 showed a pronounced drop in bond capacity for lower degrees of corrosion.

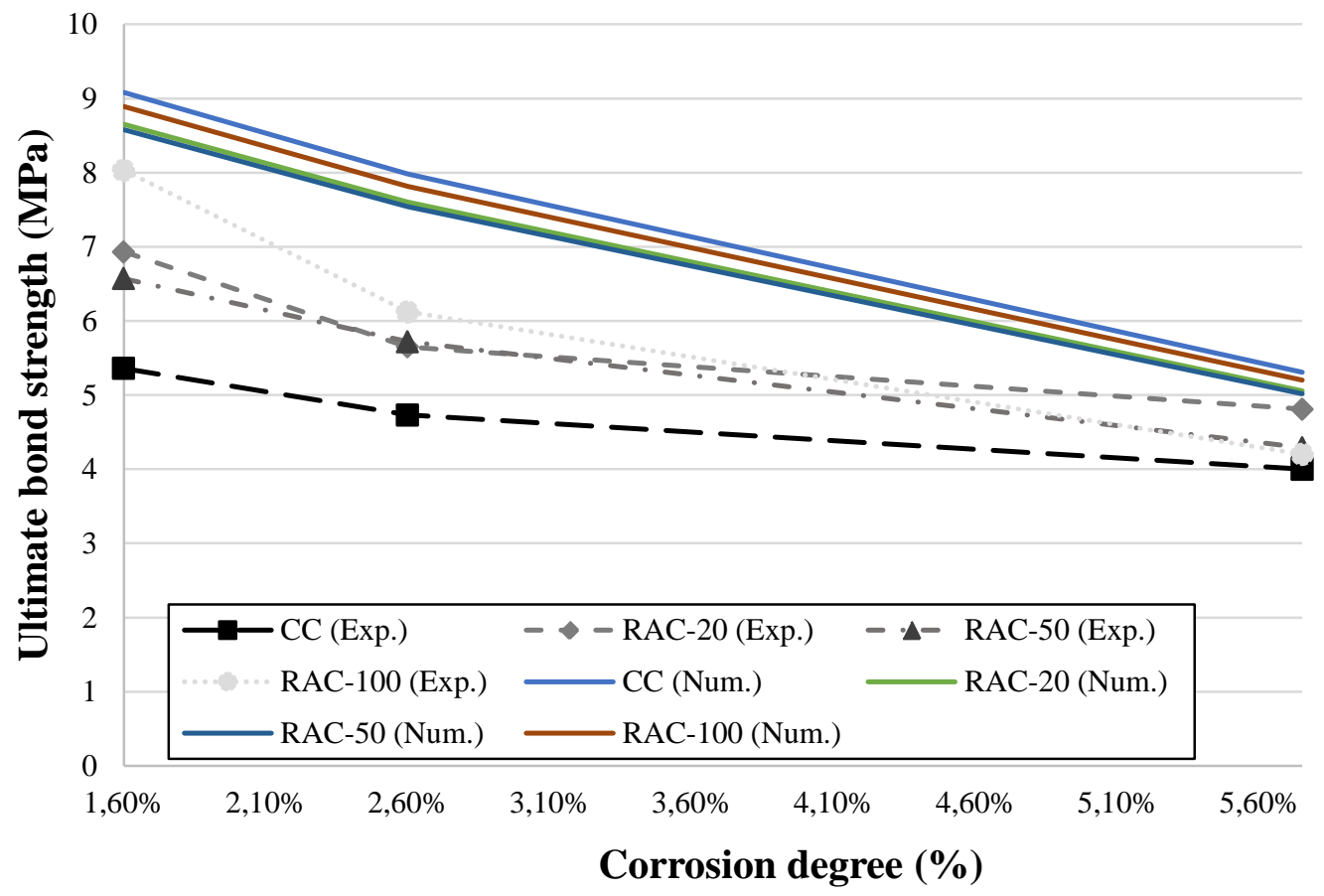

535 Figure 18. Experimental and numeral bond strength values for corroded specimens. 


\section{Conclusions}

539 Based on the results of the study, the following conclusions can be drawn:

540 (1) The bond behaviour is strongly dependent on compressive strength values. The 541 recycled aggregate concretes which had a similar compressive strength to that of 542 conventional concrete obtained similar or better bond strength.

543 (2) Recycled aggregate concretes produced employing up to 50\% of coarse recycled 544 aggregates achieved similar slip and bond strength to those of conventional $546 \quad$ suffered a substantial stiffness drop.

547 (3) On reaching the same degree of corrosion, it was noted that the initial cracking

(4) The employment of a higher amount of RCA leads to better bond strength

(6) The ultimate bond strength estimation models used for CC were adequate for the prediction of the bond strength of the RAC, when the compressive strength of the 
RCA parent concrete was found to be similar or higher to that of RAC. In order to validate an ultimate bond strength, one must take into consideration, not only its compressive strength and the percentage of RCA, but also parameters such as ratio cover/diameter and the compressive strength of RCA parent concrete. The model presented by Yalciner et al. [33] amply described quite well the bond behaviour of the corroded specimen. However, a calibration with a more extended database is needed in order to adjust the real observed behaviour accurately.

569 ranges of degrees of corrosion using slower corrosion rates. The resulting values

570 obtained from RAC, which would have been subjected to corrosion over extended

571 periods of time and consequently simulating a more natural corrosion procedure, are

572 expected to be defined as behaving even better than those obtained in this research 573 work. This improvement in behaviour consequently resulting in better adequate 574 propertie with respect to that of CC concrete.

\section{Acknowledge}

576 The authors wish to acknowledge the financial support of The Ministry of Economy and 577 Competitiveness of the Government of Spain (MINECO) for providing funds for projects 578 BIA2009-11764 as well as INNPACT project (IPT-2012-1093-310000) and the European

579 Regional Development Fund (FEDER). The financial support of Infrastructures de 580 Catalunya (ICAT) for personnel expenses is also highly appreciated. 


\section{References}

583 [1] K.Z. Hanjari, K. Lundgren, D. Coronelli, Bond capacity of severely corroded bars with corroded stirrups, Mag. Concr. Res. 63 (2011) 953-968. doi:10.1680/macr.10.00200.

[2] I. Sæther, Bond deterioration of corroded steel bars in concrete, Struct. Infrastruct. Eng. 7 (2011) 415-429. doi:10.1080/15732470802674836.

[3] D. Coronelli, K.Z. Hanjari, K. Lundgren, Severely Corroded RC with Cover Cracking, J. Struct. Eng. 139 (2013) 221-232. doi:10.1061/(ASCE)ST.1943541X.0000633.

[4] A. Muñoz Noval, C. Andrade, A. Torres, J. Rodríguez, Relation between Crack Width and Diameter of Rebar Loss Due to Corrosion of Reinforced Concrete Members, ECS Trans. 3 (2007) 29-36. doi:10.1149/1.2721428.

[5] C. Alonso, C. Andrade, J. Rodriguez, J.M. Diez, Factors controlling cracking of concrete affected by reinforcement corrosion, Mater. Struct. 31 (1998) 435-441. doi:10.1007/BF02480466.

[6] K. Lundgren, P. Kettil, K.Z. Hanjari, H. Schlune, A.S.S. Roman, Analytical model for the bond-slip behaviour of corroded ribbed reinforcement, Struct. Infrastruct. Eng. 8 (2012) 157-169. doi:10.1080/15732470903446993.

[7] K. Zandi Hanjari, K. Lundgren, M. Plos, D. Coronelli, Three-dimensional modelling of structural effects of corroding steel reinforcement in concrete, Struct. Infrastruct. Eng. (2011) 1-17. doi:10.1080/15732479.2011.607830.

[8] C. Fang, K. Lundgren, M. Plos, K. Gylltoft, Bond behaviour of corroded reinforcing steel bars in concrete, Cem. Concr. Res. 36 (2006) 1931-1938. doi:10.1016/j.cemconres.2006.05.008.

[9] M.R. Salari, E. Spacone, Finite element formulations of one-dimensional elements with bond-slip, Eng. Struct. 23 (2001) 815-826. doi:10.1016/S0141-0296(00)000948.

[10] J. Xiao, H. Falkner, Bond behaviour between recycled aggregate concrete and steel rebars, Constr. Build. Mater. 21 (2007) 395-401. doi:10.1016/j.conbuildmat.2005.08.008.

[11] S.-W. Kim, H.-D. Yun, Evaluation of the bond behavior of steel reinforcing bars in recycled fine aggregate concrete, Cem. Concr. Compos. 46 (2014) 8-18. doi:10.1016/j.cemconcomp.2013.10.013.

[12] S.-W. Kim, H.-D. Yun, Influence of recycled coarse aggregates on the bond behavior of deformed bars in concrete, Eng. Struct. 48 (2013) 133-143.

doi:10.1016/j.engstruct.2012.10.009.

[13] S. Seara-Paz, B. González-Fonteboa, J. Eiras-López, M.F. Herrador, Bond behavior between steel reinforcement and recycled concrete, Mater. Struct. 47 (2013) 323334. doi:10.1617/s11527-013-0063-z.

[14] I. Eiras López, J., Seara Paz, S., González Taboada, I., Vieito Raña, COMPORTAMIENTO ADHERENTE EN HORMIGÓN CON ÁRIDO, in: 
663

664

Comport. Adherente En Hormigón Con Árido Reciclado. Curva Tensión AdherenteDeslizamiento, ACHE - Asociación cientificotécnica del hormigón estructural, Madrid, 2014: pp. 1-10.

[15] FiB Bulletin 10 - Bond of reinforcement in concrete, 2000.

[16] L. Butler, J.S. West, S.L. Tighe, The effect of recycled concrete aggregate properties on the bond strength between RCA concrete and steel reinforcement, Cem. Concr. Res. 41 (2011) 1037-1049. doi:10.1016/j.cemconres.2011.06.004.

[17] Y. Zhao, H. Lin, K. Wu, W. Jin, Bond behaviour of normal/recycled concrete and corroded steel bars, Constr. Build. Mater. 48 (2013) 348-359. doi:10.1016/j.conbuildmat.2013.06.091.

[18] S.W. Tabsh, A.S. Abdelfatah, Influence of recycled concrete aggregates on strength properties of concrete, Constr. Build. Mater. 23 (2009) 1163-1167. doi:10.1016/j.conbuildmat.2008.06.007.

[19] T. Hansen, Recycled aggregate and recycled aggregate concrete, Second State-ofthe-art Report developments 1945-1985, Mater. Struct. RILEM. 111 (1986).

[20] T. Hansen, RILEM: recycling of demolished concrete and masonry, Report of Technical Comité 37-DRC: Demolition and Reuse of Concrete, London, 1992.

[21] M.C. Limbachiya, T. Leelawat, R.K. Dhir, Use of recycled concrete aggregate in high-strength concrete, Mater. Struct. 33 (2000) 574-580. doi:10.1007/BF02480538.

[22] K.K. Sagoe-Crentsil, T. Brown, A.H. Taylor, Performance of concrete made with commercially produced coarse recycled concrete aggregate, Cem. Concr. Res. 31 (2001) 707-712. http://www.sciencedirect.com/science/article/pii/S0008884600004762 (accessed October 16, 2014).

[23] C.S. Poon, Z.H. Shui, L. Lam, H. Fok, S.C. Kou, Influence of moisture states of natural and recycled aggregates on the slump and compressive strength of concrete, Cem. Concr. Res. 34 (2004) 31-36. doi:10.1016/S0008-8846(03)00186-8.

[24] M. Etxeberria, E. Vázquez, A. Marí, M. Barra, Influence of amount of recycled coarse aggregates and production process on properties of recycled aggregate concrete, Cem. Concr. Res. 37 (2007) 735-742. http://www.sciencedirect.com/science/article/pii/S0008884607000415 (accessed May 26, 2014).

[25] R.V. Silva, J. de Brito, R.K. Dhir, Properties and composition of recycled aggregates from construction and demolition waste suitable for concrete production, Constr. Build. Mater. 65 (2014) 201-217. http://www.sciencedirect.com/science/article/pii/S0950061814004437 (accessed August 29, 2014).

[26] C.. Poon, Z.. Shui, L. Lam, Effect of microstructure of ITZ on compressive strength of concrete prepared with recycled aggregates, Constr. Build. Mater. 18 (2004) 461468. http://www.sciencedirect.com/science/article/pii/S0950061804000388 (accessed May 29, 2014).

[27] M. Barra, E. Vázquez, Properties of concrete with recycled aggregates: influence of 
665

666

667

668

669

670

671

672

673

674

675

676

677

678

679

680

681

682

683

684

685

686

687

688

689

690

691

692

693

694

695

696

697

698

699

700

701

702

703

704

705

706

properties of the aggregates and their interpretation., in: Proceeding Int. Symp. Sustain. Constr. Use Recycl. Concr. Aggreg., London, 1998: pp. 19-30.

[28] A. Ajdukiewicz, A. Kliszczewicz, Influence of recycled aggregates on mechanical properties of HS/HPC, Cem. Concr. Compos. 24 (2002) 269-279. http://www.sciencedirect.com/science/article/pii/S0958946501000129 (accessed October 24, 2014).

[29] J.R. Jiménez, J. Ayuso, A.P. Galvín, M. López, F. Agrela, Use of mixed recycled aggregates with a low embodied energy from non-selected CDW in unpaved rural roads, Constr. Build. Mater. 34 (2012) 34-43.

http://www.sciencedirect.com/science/article/pii/S0950061812001195 (accessed October 28, 2014).

[30] J. a. Pérez-Benedicto, M. Del Río-Merino, J.L. Peralta-Canudo, M. De la Rosa-La Mata, Características mecánicas de hormigones con áridos reciclados procedentes de los rechazos en prefabricación, Mater. Construcción. 62 (2011) 25-37. doi:10.3989/mc.2011.62110.

[31] V. Corinaldesi, G. Moriconi, Influence of mineral additions on the performance of 100\% recycled aggregate concrete, Constr. Build. Mater. 23 (2009) 2869-2876. http://www.sciencedirect.com/science/article/pii/S0950061809000713 (accessed October 7, 2014).

[32] F.M. de Almeida Filho, M.K. El Debs, A.L.H.C. El Debs, Bond-slip behavior of self-compacting concrete and vibrated concrete using pull-out and beam tests, Mater. Struct. 41 (2007) 1073-1089. doi:10.1617/s11527-007-9307-0.

[33] H. Yalciner, O. Eren, S. Sensoy, An experimental study on the bond strength between reinforcement bars and concrete as a function of concrete cover, strength and corrosion level, Cem. Concr. Res. 42 (2012) 643-655. doi:10.1016/j.cemconres.2012.01.003.

[34] Instrucción de hormigón estructural - EHE-08, 2008.

[35] A. Losberg, Cracks in continuous concrete road slabs and other concrete structures locked against movements from temperature and shrinkage, 1962.

[36] M.F. Ruiz, A. Muttoni, P.G. Gambarova, Analytical Modeling of the Pre- and Postyield Behavior of Bond in Reinforced Concrete, (2007) 1364-1372.

[37] N.E. UNE, UNE-EN_10080=2006, (2006).

[38] T.E.A. El Maaddawy, K.K.A. Soudki, Effectiveness of impressed current technique to simulate corrosion of steel reinforcement in concrete, J. Mater. Civ. .... (2003) 41-47. http://ascelibrary.org/doi/abs/10.1061/(ASCE)0899-1561(2003)15:1(41) (accessed July 3, 2014).

[39] M. Badawi, K. Soudki, Control of Corrosion-Induced Damage in Reinforced Concrete Beams Using Carbon Fiber-Reinforced Polymer Laminates, J. Compos. Constr. 9 (2005) 195-201. doi:10.1061/(ASCE)1090-0268(2005)9:2(195).

[40] M. Saifullah, L.L.A. Clark, M. Sailfullah, L.L.A. Clark, Effect of Corrosion Rate on the Bond Strength of Corroded Reinforcement, in: S.A. Press (Ed.), Proc. Int. Conf. Corros. Corros. Prot. Steel Concr., University of Sheffield, 1994: pp. 591-600. 
[41] ASTM Standard G1, Standard practice for preparing, cleaning, and evaluating corrosion test specimens, (2011).

[42] T.C.H. and H. Narud, Strength of Recycled Concrete Made From Crushed Concrete Coarse Aggregate, Concr. Int. 5 (n.d.).

[43] D. Pedro, J. de Brito, L. Evangelista, Influence of the use of recycled concrete aggregates from different sources on structural concrete, Constr. Build. Mater. 71 (2014) 141-151. doi:10.1016/j.conbuildmat.2014.08.030.

[44] D. Soares, J. de Brito, J. Ferreira, J. Pacheco, Use of coarse recycled aggregates from precast concrete rejects: Mechanical and durability performance, Constr. Build. Mater. 71 (2014) 263-272. doi:10.1016/j.conbuildmat.2014.08.034.

[45] G. Andreu, E. Miren, Experimental analysis of properties of high performance recycled aggregate concrete, Constr. Build. Mater. 52 (2014) 227-235. doi:10.1016/j.conbuildmat.2013.11.054.

[46] S.-W. Kim, H.-D. Yun, Influence of recycled coarse aggregates on the bond behavior of deformed bars in concrete, Eng. Struct. 48 (2013) 133-143. doi:10.1016/j.engstruct.2012.10.009.

[47] S.-W. Kim, H.-D. Yun, Evaluation of the bond behavior of steel reinforcing bars in recycled fine aggregate concrete, Cem. Concr. Compos. 46 (2014) 8-18. doi:10.1016/j.cemconcomp.2013.10.013.

[48] Z. Dahou, Z. Mehdi Sbartaï, A. Castel, F. Ghomari, Artificial neural network model for steel-concrete bond prediction, Eng. Struct. 31 (2009) 1724-1733. http://www.sciencedirect.com/science/article/pii/S0141029609000789 (accessed March 23, 2015).

[49] Y.S. Choi, S.-T. Yi, M.Y. Kim, W.Y. Jung, E.I. Yang, Effect of corrosion method of the reinforcing bar on bond characteristics in reinforced concrete specimens, Constr. Build. Mater. 54 (2014) 180-189. http://www.sciencedirect.com/science/article/pii/S0950061813012221 (accessed March 23, 2015).

[50] L. Abosrra, A.F. Ashour, M. Youseffi, Corrosion of steel reinforcement in concrete of different compressive strengths, Constr. Build. Mater. 25 (2011) 3915-3925. http://www.sciencedirect.com/science/article/pii/S0950061811001632 (accessed February 13, 2015).

[51] Y. Zhao, J. Dong, Y. Wu, H. Wang, X. Li, Q. Xu, Steel corrosion and corrosioninduced cracking in recycled aggregate concrete, Corros. Sci. 85 (2014) 241-250. http://www.sciencedirect.com/science/article/pii/S0010938X14001991 (accessed November 25, 2014).

[52] Model Code 2010-Final draft, The international federation for structural concrete, FIB. Bulletin No 52 Fib, 2; Lausanne, 2012. 